\title{
Pain Mechanisms: A Commentary on Concepts and Issues
}

\author{
Edward R. Perl \\ Department of Cell \& Molecular Physiology, University of North Carolina School of Medicine, \\ Chapel Hill, NC 27599-7545, United States
}

\section{Abstract}

This commentary on ideas about neural mechanisms underlying pain is aimed at providing perspective for a reader who does not work in the field of mammalian somatic sensation. It is not a comprehensive review of the literature. The organization is historical to chronicle the evolution of ideas. The aim is to call attention to source of concepts and how various ideas have fared over time.

One difficulty in relating concepts about pain is that the term is used to refer to human and animal reactions ranging from protective spinal reflexes to complex affective behaviors. As a result, the spectrum of "pain"-related neural organization extends to operation of multiple neuronal arrangements.

Thinking about pain has shadowed progress in understanding biological mechanisms, in particular the manner of function of nervous systems. This essay concentrates on the evolution of information and concepts from the early $19^{\text {th }}$ century to the present. Topics include the assumptions underlying currently active theories about pain mechanisms. At the end, brief consideration is given to present-day issues, e.g., chronic pain, central pain, and the view of pain as an emotion rather than a sensation. The conceptual progression shows that current controversies have old roots and that failed percepts often resurface after seemingly having been put to rest by argument and evidence.

At the outset there is a semantic issue. Experiences evoked by physical injury of the body and those produced by disturbing mental images are similarly called "painful." Reactions produced by tissue injury typically include features signaling intensity and location, whereas those "pain" experiences resulting from strictly mental processes lack or poorly express these attributes. The latter often are associated with affective or motivational processes. This shared nomenclature represents a clue to the nature of circumstances we variously label "pain." Could redefinition of the term "pain" as the experience of suffering or of discomfort, regardless of cause, link together these situations? This would be consistent with its employment to indicate both sensory aspects of tissue injury and the experiences associated with mental distress.

It is evident that ideas about pain and its mechanisms have changed in company with enlightenment about the world in general and the mammalian nervous system in particular. To trace these changes, this commentary begins with an outline history of the development of concepts about biological mechanisms relevant to pain. Then comments turn to more

() 2011 Elsevier Ltd. All rights reserved.

(919) 966-3560 (phone), (919) 966-3870 (fax), erp@med.unc.edu.

Publisher's Disclaimer: This is a PDF file of an unedited manuscript that has been accepted for publication. As a service to our customers we are providing this early version of the manuscript. The manuscript will undergo copyediting, typesetting, and review of the resulting proof before it is published in its final citable form. Please note that during the production process errors may be discovered which could affect the content, and all legal disclaimers that apply to the journal pertain. 
recent concepts and current questions. The reader interested in more detail about older issues should consult Dallenbach (1939) and monographs by Keele (1957) and by Rey (1993).

\section{Distant Times}

Direct evidence on prehistoric thought about pain does not exist; however, beliefs held in present-day primitive societies provide leads. In these societies pain is explained in magical or religious terms. In such cultures, beliefs often include that the intrusion of objects or spirits into the body is the source of the unpleasant or distressful experience. In this context, prevention or treatment involves removal or blocking the entry of objectionable material and therapy relies on spells or calls upon deities (Keele, 1957).

Early societies had limited insight into anatomy and functions of parts of the body, although the heart, with its regular pulsations, was recognized as essential for life. In Egypt, prior to $2000 \mathrm{BC}$, the heart was given preeminence as the organ conveying life and human capability. The brain was considered of little import, as indicated by the Egyptian practice of carefully saving the heart and discarding the brain when embalming a body. The Chinese canon of medicine, Nei Ching, dating from about $2600 \mathrm{BC}$, also gave major importance to the heart or other organs in controlling the streams of forces (yin and yang) presumed to regulate life (Keele, 1957). The brain was ignored. An excess of yang was presumed to be a cause of pain and to be injurious to the spirit. The Nei Ching states pain to be evident when vessels containing blood and air are obstructed, allowing accumulation of yang.

Greek philosophers of classical antiquity (600-200 BC) had diverse ideas about pain (Keele, 1957; Rey, 1993). Alcmaeon (500-450 BC) of Croton studied the senses carefully and proposed that each mode of sensation represents the entrance of particles carrying the essential character of a particular experience - light, smell, sound - to special receptive structures in the body, which transmit the particles to the brain. This was an early suggestion that sensation represented a function of the brain rather than of the heart. Democritus (460-362 BC) developed a concept of atoms as the material of the earth and air, arguing that such atoms had special properties in their structure and arrangement in space to articulate with receptors of the body giving rise to the modes of sensation. He proposed pain to represent an intrusion by atoms with a sharply hooked angularity, thereby favoring a special kind of activation as responsible for pain.

Aristotle (384-322 BC) had major impact upon future thinking about life and sensation; however, he lacked direct information about anatomy. Vivisection and dissection of the dead were not accepted by Athenian society of his time. Aristotle held for a cardiac basis of sensation, believing the heart to be the center for thinking and consciousness. In ignoring the brain's function in sensation, emotion, and intellect, he disregarded the views of Alcmaeon, Democritus, and Plato. Yet, Aristotle was deeply interested in sensation and suggested touch to have special importance. To Aristotle, touch was one of five principal senses, the others being sight, hearing, smell, and taste. He believed touch to be closely related to pain. In his view, pain stemmed from the sensitivity of animals and their organs rather than modes of stimulation. Aristotle's concept of the cardiac basis of sensation and consciousness held sway in Western European thinking for many centuries, in part because of support of his views by the Roman Church (Keele, 1957). Aristotle expressed the idea that animals could survive only if their bodies possessed the sensation of touch. He explicitly recognized the relationship between tissue injury and pain. He viewed the heart's characteristics as a central factor in sensory responsiveness. When a heart is hard and dense, he proposed lack of sensitivity by the individual. The converse, when a heart is soft and pliable, yields greater responsiveness. The modern use of the terms "hard-hearted" and "soft-hearted" may have origin in these precepts. 
The physician-philosophers of ancient Alexandria who followed Aristotle did not agree with his views about the heart's role, having insights from cadaver dissection, long practiced there. Herophilus (335-280 BC) proposed the brain to be the organ of consciousness and sensation, recognizing that peripheral nerves led from the spinal cord to various tissues and were pathways serving sensation and control of movement. Herophilus's views represented the background for studies and conclusions by the famous surgeon-physician Galen (130-201 AD), who championed the idea that the brain was the paramount organ for consciousness and sensation. Galen considered the heart to be a pump distributing material via the arteries. He understood the distribution of spinal and cranial nerves, agreeing with earlier findings that every organ is supplied by a triad of nerve, artery, and vein. He noted an extensive neural supply to parts of the body that were exposed to outside stimulation, proposing that pain is a warning to avoid harmful circumstances, the view expressed earlier by Aristotle. Galen extended insights provided by anatomy with observations from vivisection on newborn pigs. He found complete transverse division of the spinal cord eliminates reaction to stimuli applied distal to the level of the cut and joined Herophilus in proposing the spinal cord to be a conduit for messages between the brain and the tissues of the body.

Much of the understanding Galen brought to Rome from his medical experience in Pergamon and Alexandria and from the work of earlier philosopher-physicians documented in Alexandria's famous library, was lost to Western Europe with the collapse of the Roman Empire and the resultant fragmentation and decentralization of the Middle Ages (400-1400 $\mathrm{AD})$. In contrast to the loss of zeal for probing new horizons in Western Europe during the Middle Ages, in the East, the Muslim faith flourished and fertilized intellectual life. The golden age of Muslim thought produced the philosopher-physician Avicenna (Ibnsina, 980-1038 AD), born and educated in Persia. He became much admired and sought after as an advisor by Arab courts of the time. He wrote extensively in Arabic, including his famous Canon, which represented a compilation of medical knowledge from his time and earlier periods (Gruner, 1930). The Canon, translated into western languages, served as a medical text in Europe for centuries. Avicenna recognized the nervous system as a source of consciousness and sensation. He expressly formulated the idea that pain is a specific sense, distinct from touch. He was led to this view by the dissociation of deficits in the capacity to experience pain and feel touch or other somatic sensory experiences that occur in instances of human pathology. A given patient could lose touch sense and keep pain, or the converse, retain touch and lose pain

\section{The Renaissance and the Age of Reason}

Early in the Western Renaissance, a man for all seasons, Leonardo da Vinci (1452-1519) had particular interest in nerves and nervous tissues, exploring their anatomy by careful dissection of human cadavers. His remarkable anatomical drawings show that he appreciated the role of peripheral nerves in carrying messages to and from the body. He demonstrated substantial insight into relationships between peripheral nerves, roots of the spinal cord, and the spinal cord's function as a conductor of information between the periphery and the brain. For Leonardo, pain was a sensation mediated by nerves that also carry information about touch (Figure 1).

With the flowering of the Renaissance, the brain's external and internal relationships were actively examined by dissection and speculation; however, advances during the $15^{\text {th }}$ and $16^{\text {th }}$ centuries A.D. were largely morphological. Understanding the brain's functioning awaited new approaches and better appreciation of basic biology. In Descartes's (1596-1650) $17^{\text {th }}$-century concept of the body as a machine, a pathway was postulated for special particles from the outside to enter the body and to be transported to the brain for the 
production of pain. The idea of particles was a concept popular in the early Renaissance, holding that elements of the environment enter the body to be carried by nerves to the brain. A century after Descartes, Isaac Newton (1642-1727) suggested that sensation resulted from vibrations of a subtle spirit in the filaments of nerves supplying the external organs of sense. $\mathrm{He}$ further proposed that activity from the brain was carried to the muscles through nerves by similar vibrations of an integral material. Thus, Newton anticipated discovery of the nerve impulse and inspired a fellow countryman, Thomas Hartley (1705-1757), to propose a theory of nervous function based upon vibrations produced in the environment and then transferred to substances contained in the nerves, spinal cord, and brain. These views of nervous messages as transitory changes in the properties of the nerve fibers themselves represented a conceptual breakthrough.

\section{Sensory Nerves}

Classic Alexandrian philosophers and physicians in the $3^{\text {rd }}$ century BC benefited from the freedom to dissect cadavers, proposing nerves to have specific functions, for example, motor or sensory. Galen, who learned much from the insights provided by the Alexandrians, also believed some peripheral nerves to be sensory and others motor. Whereas in general, such concepts proved to be incorrect, in particular cases it proved to be a seminal insight. In 1811, Edinburgh anatomist Charles Bell (1774-1842) published a monograph, "The Idea of a New Anatomy of the Brain; Submitted for the Observations of His Friends," (Figure 2), in which he proposed differences in function between the dorsal and ventral roots of the mammalian spinal cord. Bell suggested motor activity to depend on the ventral roots. François Magendie, from across the English Channel, is widely credited for demonstrating that the dorsal spinal roots are afferent (Cranefield, 1974; Magendie, 1822). Bell and Magendie (and their supporters) vied for credit in unearthing the functions of the spinal roots, a controversy that spawned numerous commentaries (Cranefield, 1974). Together, Bell's and Magendie's discoveries provided powerful tools for work to come on functions of the spinal cord and ultimately on pain mechanisms.

Bell went further in his 1811 treatise by commenting upon the specificity of function by peripheral nerves:

The nerves of sense and nerves of motion, and the vital nerves, are distinct throughout their whole course, though they seem sometimes united in one bundle ... It is admitted that neither bodies nor images of bodies are in the brain. It is indeed impossible to believe that color can be conveyed along a nerve, or vibration in which we suppose sound to consist can be contained by the brain; but we can conceive, and have reason to believe, that an impression is made of the organs of outward sense when we see, hear, or taste, and in this inquiry it is most essential to observe that while each organ of sense is provided with the capacity for receiving certain changes to be played upon as it were, yet each is utterly incapable of receiving the impression destined for another organ of sensation.

In this monograph, Bell reasons in favor of functional specificity by sensory neurons. Promotion of that concept, however, is generally attributed to Johannes Müller, who in 1840 published a series of rules about functioning by sensory neurons. A century later, Dallenbach (1939) commented that Müller's postulates supporting five classes of sensation contain little beyond Aristotle. Nonetheless, Müller, in outlining the concept of specific afferent function, effectively eliminated the idea that sensory nerves conduct to the brain properties or particles of objects perceived, by providing evidence that one kind of stimulation produces quite different effects when applied to different sensory organs, e.g., mechanical pressure to the eye evokes a flash of light, not the sense of pressure. The concept of dedicated function for sensory nerves provided a point of departure for much 
investigation of sensation in subsequent years. Although Müller did not comment particularly on pain, his ideas raised the possibility that pain might be associated with specific nerves (Dallenbach, 1939; Keele, 1957).

Electrical changes were presumed to underlie some function of nerve and muscle in the first half of the $19^{\text {th }}$ century, however, proof of this awaited development of more sensitive recording devices. In about 1820 the galvanometer came into being, making it possible to measure small changes in electric potential and current. With this new tool in 1848, Du Bois-Reymond (1818-1896) documented that nerve activity had a transient electrical change associated with it. That provided reality to Newton's notion of vibrations carried by the substance of nerves. Discovery of nerve action potentials was consistent with a message system common to all sensory nerves and lent weight to Müller's thesis that differences between sensory nerves represent distinctive peripheral origins and central terminations. That raised the issue of whether one set of nerve fibers or separate and distinct fibers underlay different somatic sensory experiences of touch, heat, cold, pain, and itch. Answers to this question needed new approaches and techniques.

\section{Spinal Pathways}

The latter part of the $19^{\text {th }}$ century saw intensive work on spinal pathways involved in somatic sensation and pain. In 1858 Moritz Schiff, a student of Magendie, described effects of spinal cord lesions on reactions to afferent stimulation in dogs and cats that convinced him of separate spinal pathways for discriminative tactile sensation, movement detection, pain, and temperature sense. He also reported crossing of the spinal pathway for pain and thermal sense. On the basis of his findings, Schiff proposed pain to be an independent sensation, the concept put forth in the $11^{\text {th }}$ century by Avicenna to account for dissociation of deficits in pain, tactile and temperature senses in human disease and injury.

Apparently Schiff was unaware that Galen had studied the effects of spinal cord lesions upon motor function many centuries before (Dallenbach, 1939; Keele, 1957). BrownSéquard (1860), on the other hand, knowing of Galen's experiments, analyzed the sensory effects of Galen's spinal cord lesions a few years after Schiff's report. Initially, BrownSéquard concluded that sensation was lost whenever the grey matter of the spinal cord was lesioned, whereas body sensation persisted after major injuries to the spinal white matter. Subsequently, he agreed with Schiff that different sensory modes (tactile and pain) were dependent on distinctive pathways within the spinal cord and that the path for pain involved the contralateral spinal white matter (Brown-Séquard, 1868). The British neurologist William Gowers (1878) applied the analyses of Schiff and Brown-Séquard to human cases, supporting the notion of a crossing of the spinal pathway for pain. By late in the $19^{\text {th }}$ century many clinicians accepted the concept of a crossed spinal pathway for pain; however, not all observers were convinced. For instance, Charcot, the great French neurologist, in 1881 argued that clinical observations and pathological anatomy indicated that no partial lesion of the spinal cord blocked transmission of activity responsible for somatic sensation. In contrast, he concluded that the clinical evidence favored the view that voluntary movement can be compromised by particular limited spinal lesions.

For several decades after Schiff's and Brown-Séquard's observations, the intimate organization of the nervous system remained an open issue. Two leading anatomists of the time, Camillo Golgi (1843-1926) and Santiago Ramon y Cajal (1852-1934), disagreed about whether the neural elements forming the central nervous system (CNS) were discrete cells or represented a syncytium with continuity of protoplasm of the constituent elements. Cajal was an advocate for the idea of discrete cells, while Golgi strongly argued for a syncytium (Golgi, 1885; Ramon y Cajal, 1909). The cell theory of tissue structure, applied to the 
nervous system by Theodor Schwann (1847) and Wilhelm Waldeyer (1891), supported Cajal's view. Physiologists of the time, e.g., Charles Sherrington, vigorously favored Cajal's position and proposed membrane-delineated junctions between neurons (Foster and Sherrington, 1897).

In the late $19^{\text {th }}$ century the experimental animal studies by Schiff and Brown-Séquard were complimented by clinical and anatomical observations. Gowers provided additional evidence for crossing of the pathway for pain in the spinal cord from a carefully analyzed case (Gowers, 1878). Ludwig Edinger, a German anatomist, using the staining techniques of Golgi and Cajal, defined a crossed afferent tract in lower vertebrates. Afferent fibers of the dorsal roots were noted to contact cells of the ipsilateral spinal dorsal horn. In turn, dorsal horn neurons sent processes across the midline, which were found to run rostrally in the ventrolateral spinal white matter (Edinger, 1890; 1892). Edinger (1890) also noted that dorsal roots divide into differently composed medial and lateral bundles near their junction with the spinal cord. This latter feature came to play an important part in the subsequent demonstration of a relationship between the fibers in the dorsal-root divisions and pain. Connecting the crossed path to pain, however, came cautiously. Gowers did not explicitly link Edinger's lateral spinal tract to the pathway he believed transmitted activity for human pain. A turning point came in 1905 when W.G. Spiller, an American neurologist, predicted the location of a lesion in the lateral spinal white matter that interfered with the evocation of pain by stimulation of the contralateral body. This correct prediction of a lesion causing loss of pain proved strong evidence linking a crossed spinal pathway to human pain.

In the first half of the $20^{\text {th }}$ century, evidence became compelling that Edinger's crossed spinal pathway is crucial for conveying activity responsible for pain. One step was Spiller's and Martin's 1912 introduction of the idea of a surgically produced ventrolateral spinal cord lesion (cutting a chord of the spinal circle, i.e., chordotomy or cordotomy) to treat persisting, otherwise intractable, pain of peripheral origin. Later, retrograde degeneration of neurons in the spinal cord after cordotomies indicated the origin of this pathway to be in the contralateral spinal dorsal horn with axons crossing in the spinal ventral commissure (Foerster and Gagel, 1932; Kuru, 1949). Fibers of the spinal ventrolateral white matter were shown to project to the ipsilateral thalamus (Mott, 1895). A crossed spinothalamic pathway and a direct spinal projection to the thalamus with primary importance for pain became $20^{\text {th }}$ century neurological dicta.

\section{Intensity and the Punctate Nature of Skin Sensibility}

In the latter part of the $19^{\text {th }}$ century, not all attention was directed at definition of CNS pathways for pain-related activity. A leading German neurologist, Wilhelm Erb, whereas agreeing with the sensory nature of pain, articulated what became known as the intensive theory (Erb, 1874). Erb reasoned that pain was the outcome of any type of strong sensory stimulation, arguing that intense activation of any sensory modality is unpleasant. A relationship between the mechanisms of pain and intensity of stimulation had been anticipated by earlier commentators, e.g., Erasmus Darwin (see Dallenbach, 1939) and the physiological psychologist Ernst Weber (1795-1878).

Late in the $19^{\text {th }}$ century a new consideration came into play. In 1884 Magnus Blix, a Swedish psychophysicist, described discontinuous sensitivity in human skin. Blix noted that mechanical stimulation with a small probe of spot-like loci on human skin evoked pain, whereas the same stimulus to adjacent regions gave rise to different sensory experiences. Subsequently, Blix recognized spots for warmth, cold, and pressure, but, in contrast to his earlier report, not for pain. The German psychophysicist Alfred Goldscheider (1884) in similar studies initially did not describe pain spots, but later altered his view and favored 
them. Still later, Goldscheider again shifted position, denying pain spots and proposing that pain was produced by strong stimulation of pressure spots (Dallenbach, 1939).

Another German psychophysicist, Max von Frey, entered this shifting field, adding data from quantitatively defined localized skin pressure produced by calibrated flexible probes constructed of animal vibrissa hairs of various stiffness. (Modern incarnations of graduated, flexible mechanical probes used for punctate skin stimulation are often referred to as von Frey stimulators.) Von Frey interpreted his observations on sensations evocable by calibrated punctate mechanical stimuli to strongly support the presence of four kinds of skin sensory spots: pressure, cold, warmth, and pain. He explicitly proposed specific receptive structures to underlie each kind of spot-like area (Frey, 1894; 1895; 1896), including a special afferent ending for pain. Von Frey's views complemented Schiff's concept of pain as a specific sensation and were supported by prominent neurologists including Weir Mitchell in the United States and Henry Head in England (Keele, 1957). Von Frey went a step further. He circumstantially correlated the distribution (number) of modality-specific sensory spots with the distribution of histologically defined endings in given regions of the skin. On this basis, he associated pressure sense with hair follicles and Meissner corpuscles, cold sense with Krause end-bulbs, warmth with Ruffini end-organs, and pain with free nerve endings. Although soon challenged and eventually shown to be mostly incorrect, these correlations became widely cited in the $20^{\text {th }}$ century and found their way into textbooks of physiology and neurology.

The late $19^{\text {th }}$-century focus on point-like sensibility in the skin has a possibly related parallel in artistic painting. Georges Seurat (1859-1891), a founder of neoimpressionist painting, had great interest in the science of visual perception. He began use of a meld of point-like spots to create impressions of complex objects, initiating the technique of pointillism painting in 1883-1884. That date coincides with Blix's and Goldscheider's early work on the skin spots for different sensation. Coincidence or relationship?

The end of the $19^{\text {th }}$ and the beginning of the $20^{\text {th }}$ century saw vigorous debate on von Frey's correlations between sensation and specific cutaneous afferent organs. More general issues were also in question: are there special sense organs for pain, is pain a specific sensory experience, does pain represent the outcome of strong stimulation of sense organs responsible for other experiences? These questions were company to active explorations of nervous-system structure and function. Seminal contributions to neural functioning were made at the turn of the century by the English neurophysiologist Charles Sherrington (1857-1952), who - among other ideas - provided evidence for the existence of inhibition in CNS functions (Foster and Sherrington, 1897). Sherrington also provided a common ground for the various stimuli capable of evoking pain. It had been argued that pain was not an independent sense because it can be elicited by widely different stimuli (e.g., mechanical, chemical, thermal) in contrast to the defined stimuli for other sensations. Sherrington (1906) countered with the logic that a common feature of events evoking pain is damage of tissue. He suggested that all stimuli capable of injuring tissue be labeled "noxious" and coined the terms "nociception" and "noci-ceptor," to describe unique activity by selective afferents. Thereby he defined a common ground for pain-evoking stimuli.

Early in the $20^{\text {th }}$ century, relationships of dorsal-root fibers to CNS pathways were clarified. S. Walter Ranson $(1913 ; 1914 ; 1915)$, using histological stains based on silverimpregnation, extended Edinger's observations on the medial-lateral division of dorsal roots. He called attention to the lateral division's fibers projection to the spinal substantia gelatinosa and Lissauer's dorsolateral spinal tract. Ranson agreed with Edinger that the lateral division of dorsal roots is composed largely of thin fibers, which heavily terminate in the outer layers of the spinal dorsal horn. Ranson and Billingsley (1916) linked the lateral 
division to pain-related reactions in experimental animals by the selective effect of lesions at the dorsal-root entry zone. Division of the dorsal root lateral fibers at their junction with the spinal cord eliminated nociceptive reactions to noxious stimuli. Division of the medial fibers spared nociceptive responses (Figure 3).

\section{Action Potentials and Afferent Signaling}

In the $20^{\text {th }}$ century, electrical signs of nervous activity became an important tool in establishing function. It was known that electrical changes were associated with activity in peripheral nerves, however, the speed at which such changes took place was too great to be captured by the available recording devices. Pioneering studies by Herbert Gasser and Joseph Erlanger on nerve conduction (Gasser and Erlanger, 1922; Erlanger et al., 1924) led to their development and use of the cathode-ray oscilloscope to record rapid electrical changes. With this new tool they described the compound action potential of peripheral nerve evoked by a brief electrical pulse. They provided evidence that the composite electrical signal represented the summation of action potentials of individual fibers distributed in time according to conduction velocity. The several deflections of the compound (composite) potential are named alphabetically according to their appearance in time: $A$ for the fastest fibers, $C$ for the slowest group, a nomenclature that still is employed. The conduction velocity of group activity in peripheral nerve fibers proves to be directly related to the cross-sectional diameter of the constituent nerve fibers. The $A$ or first deflection is produced by activity in myelinated fibers, with the thicker fibers conducting more rapidly than thinner ones (Erlanger et al., 1924). The $C$ deflection (slowest) was later linked to unmyelinated fibers (Bishop et al., 1933; Clark et al., 1935; Erlanger et al., 1924; Gasser, 1955).

Manipulation of the stimulus characteristics differentially affect components of the compound potential, features that have been employed to correlate activity in categories of fibers to pain and pain-like reactions. Afferent fibers in peripheral nerve have thresholds to brief electrical pulses inversely proportional to their cross-sectional diameter. Conversely, chemical agents such as cocaine or procaine block conduction by thin fibers at lower concentrations than is effective for thick fibers. Such differential effects on components of the compound action potential were used to correlate activity in a subset of afferent nerve fibers to particular reflex and sensory reactions (Clark et al., 1935; Heinbecker et al., 1933; Landau and Bishop, 1953; Lewis et al., 1931; Thunberg, 1901; Zotterman, 1933). Pain has been consistently related to activity in the more slowly conducting myelinated and the unmyelinated peripheral afferent fibers. Moreover, more than one category of afferents is linked to nociceptive reactions and pain. As early evidence for the latter, brief application of a hot or sharp object to human skin gives rise to two distinct experiences of pain, one occurring almost immediately and a second notably delayed (Lewis and Pochin, 1937). The difference in latency between "first" and "second" pain shortens with reduction of the distance between the stimulus application and the spinal cord. The latter is consistent with mediation of the evoked pains by afferent fibers with different conduction velocities (Figure 4).

Understanding that conducted action potentials in primary afferent fibers represent signals to the CNS about peripheral events provides a powerful tool for investigation of sensation. E.D. Adrian, a pioneering British physiologist, recorded nerve action potentials from thin filaments of peripheral nerve in the 1920s, concluding that impulses in the afferent fibers were evoked by particular forms of peripheral stimulation. These extracellular recordings of electrical activity were concluded to indicate that, under constant conditions, activity of a particular nerve fiber appears as impulses of a given amplitude and shape. Reports from Adrian's laboratory in the mid-1920s are based on electrical records interpreted as 
evidencing selective excitation of impulses in certain fibers by specific stimuli (Adrian, 1926a; b; Adrian and Zotterman, 1926). On the other hand, these recordings were not universally convincing of that interpretation.

The American psychologist J.P. Nafe $(1929 ; 1934)$ pointedly disagreed with the interpretation of early electrophysiological recordings from primary afferents as indicative of specialized receptive function. Nafe proposed instead that the recordings from peripheral nerve showed differing patterns of activity to particular forms of stimulation. He suggested an arrangement for somatic sensation based upon such patterns of activity. The presumed patterns were represented by the frequency and timing of discharge of individual fibers in relation to impulses from other fibers of the population. The pattern concept, like the intensive theory, presumes no specialization of afferent fibers to reflect particular forms of stimulation. Thus, in the early 1930s there were three main ideas about the relationship of primary afferent activity to pain: specific, selectively responsive sense organs; the intensity concept; and the newly conceived pattern proposal. All viewed pain as a sensory phenomenon. At this juncture pain as an affect was not in the mainstream of contention about mechanisms.

The challenge posed by Nafe and his pattern hypothesis evoked reactions from Adrian's laboratory and other physiologists. With improvement of techniques, better records of action potentials from individual afferent fibers were obtained. In general, these recordings were interpreted to be consistent with selectivity of response to the type of stimulation by different kinds of primary afferent neurons (Adrian and Bronk, 1928). One study represented a noteworthy test of the Erb-Goldscheider intensive theory for pain. Adrian, Cattell, and Hoagland (1931) showed that generation of maximal discharge frequencies in mechanosensitive afferent fibers of the skin of intact or decerebrate frogs by rapidly repeated, innocuous puffs of air, does not evoke withdrawal or other reactions typical of nociceptive responses. In contrast, a pinprick or a drop of acid on the same area of skin elicits vigorous withdrawal. Therefore, intense (maximal) activity of sense organs responsive to innocuous stimuli does not by itself evoke pain-related reactions, negating a basic tenet of the intensive theory.

In the 1930s, Yngve Zotterman, Adrian's one-time trainee, reported that some mammalian C-fibers respond to innocuous mechanical stimuli while others require strong stimulation for activation (Zotterman, 1936; 1939). These reports made the link between thin-fiber activity and pain less clear. Therefore, in 1940 the specific sensory concept for pain faced problems. In particular, documentation and characterization of afferent fibers that are selectively nociceptive was lacking.

\section{The Nocifensor Proposal}

Electrophysiological studies of nerve conduction and afferent signaling in the 1930s were paralleled by analyses of human sensation. For example, Thomas Lewis, a prominent British cardiologist, actively explored human skin pain. His observations led to the proposal of a novel mechanism for cutaneous hyperalgesia, the lowered threshold and enhanced pain evoked by mechanical stimulation of injured skin. Lewis noted that the immediately enhanced response is followed by a spread of tenderness to adjacent undamaged skin. The spread of this secondary skin hyperalgesia does not cross a line of local anesthetic, an observation taken as evidence for spread of the increased sensitivity to be dependent upon active nerve conduction. The action potentials in the peripheral branches of cutaneous nerves were presumed to cause release of substances excitatory to nerve. In his interpretation, Lewis proposed that the hyperalgesia after skin injury is akin to hyperalgesia and vascular dilatation produced by stimulation of the peripheral end of divided cutaneous 
nerves (Lembeck, 1987; Lewis, 1937). Lewis postulated existence of an unusual innervation in the skin by two networks of dorsal-root nerve fibers, including one that does not convey activity leading to sensation. He labeled the latter network the "nocifensor system" and proposed it to underlie the spread of hyperalgesia and to have a role in vascular effects. In the nocifensor hypothesis, the sensory component of cutaneous innervation is mediated by a separate class of dorsal-root nerve fibers. Chemical agents released by activity in the nocifensor network are presumed to make the sensory cutaneous nerve fibers more excitable.

Morphological or physiological evidence supporting the kind of neural network envisioned for the nocifensor concept failed to materialize (Woollard et al., 1940). On the other hand, more modern studies confirm that antidromic activity in nerve fibers of the skin produces a vasodilatation mediated in part by peptides (Substance P, CGRP) released by certain dorsal root nerve fibers (Lembeck, 1987). The idea of antidromic spread of impulses in dorsal-root fibers has a long history (Bayliss, 1902) and is incorporated in the nocifensor concept. Peripheral nerve fibers branch. An impulse generated in a peripheral nerve fiber on reaching a branch point could spread in a central (orthodromic) direction and/or antidromically toward the periphery. Whereas the nocifensor proposal has received relatively little attention for some years, antidromically released substances (peptides) have been established as part of the mechanisms leading to inflammation after injury (Lembeck, 1983). The resultant interaction between afferent terminals, tissue damage, and inflammation indicates that innervation of the skin has a complex relationship to injury.

Lewis's nocifensor proposition prompted a histological search for anatomical evidence for appropriate cutaneous nerve networks. These histological explorations also tested predictions by von Frey relating defined neural structures in the skin to the mode of sensory experience (Woollard et al., 1940). The morphological surveys did not yield evidence in favor of a special cutaneous neural network or of a correlation between morphologically recognizable structures and specific sensation (Sinclair, 1955; Sinclair et al., 1952; Weddell, 1955; Woollard et al., 1940). The absence of findings relating particular sensory structures of the skin to modes of sensation led to vigorous proposals for mechanoreceptive cutaneous sensation and pain to represent the product of special patterns of nerve activity, concepts similar to those postulated by Nafe (1934) several decades earlier. Thus, the writings in the 1950s by Weddell (1955), by Sinclair (1952), and their colleagues (Sinclair et al., 1952) represented serious challenges to the idea of pain as a specific and independent sensation.

Numerous descriptions of the responsive characteristics of individual peripheral afferent fibers appeared from 1930 to 1960. Most of these analyses provide evidence that afferent fibers with distinctive responses to different natural stimuli exist in the innervation of various tissues. Further, that functionally defined categories of afferent fibers have distinguishing features (e.g., Bessou and Laporte, 1961; Hunt and McIntyre, 1960; Iggo, 1959a; b; 1960; Maruhashi et al., 1952; Matthews, 1933; Paintal, 1957; Zotterman, 1936; 1939). A small proportion of the primary afferent fibers in these studies were fibers requiring strong "natural" stimuli for activation (e.g., Iggo, 1959b; Figure 5); however, evidence for a coherent class of nociceptive afferent units failed to emerge.

\section{Descending Modulation}

The link between nociception and pain was also under fire in the 1950s. Henry Beecher, an anesthesiologist who served in the American forces during World War II, reported that men severely wounded in the battlefield often did not complain of pain when they were brought to triage. Those observations led to a view that pain is not a necessary concomitant of tissue injury (Beecher, 1959). 
Another consideration for pain mechanisms reflects the control of ascending afferent messages by higher centers. Modulation of spinal neuronal excitability by supraspinal centers was initially noted by Sherrington in animal reflex studies (1906). For example, in the decerebrate cat there is a potent suppression of flexor motor neurons and the flexor reflex. This pattern is abolished or reversed by blocking of conduction in pathways located in the dorsal half of the spinal cord. The flexor reflex in its usual form is nociceptive (Sherrington, 1906; Eccles and Lundberg, 1959; Kuno and Perl, 1960).

Central modulation of spinal cord afferent activity was postulated in 1926 by Fulton. In an extensive survey in 1954, Hagbarth and Kerr provided experimental documentation of the effects of CNS stimulation upon ascending spinal afferent conduction. They showed that stimulation of various brain regions, including the medullary reticular formation, the cerebral cortex, and the cerebellum, could powerfully suppress ascending afferent activity. This feature was linked to pain and nociception by Reynolds's dramatic 1969 report that stimulation in the midbrain periaqueductal grey (PAG) region of a rat permitted extensive surgery without other anesthesia. It is important to note that animals with analgesia produced by electrical stimulation of the brain stem site do respond to other afferent input. Reynolds's finding caught the attention and the imagination of numerous investigators and clinicians. Subsequent work established that parts of the PAG are connected to the ventromedial medulla. PAG stimulation was shown to activate descending projections to the spinal dorsal horn, suppressing nociceptive responses (Fields et al., 1977; Jones, 1992; Mason, 2001). The establishment of opioid receptors and endogenous opioids led to linking the descending modulation of nociceptive pathways to action of opioid receptors on neurons of the spinal dorsal horn (Fields et al., 1977; Fields et al., 1983).

Much work on descending afferent modulation has focused on nociception and pain (Mason, 2005). Considerable attention also has been given to "stimulus-based analgesia," apparently in the hope of evolving techniques for control of unwanted pain. Mason $(2001,2005)$ points out that stimulation of loci in the PAG or in the ventro-medial medulla also potently modulates autonomic output. Endogenous opioid activity apparently plays an important part in descending antinociception and analgesia; however, less attention has been given to profound changes in other bodily function produced by opioids. The effects of stimulation of the ventro-lateral medulla correspond to actions noted as part of sleep-wakefulness cycles. Recently, descending control of afferent information has been proposed to be part of general neural systems that modulate or reduce afferent input to higher centers under a variety of circumstances (Mason, 2005).

\section{The Gate Control Theory}

The mid-20 $0^{\text {th }}$-century postulates of the absence of specific relationship between sense organs and sensation in somatosensory signaling was the stage for a 1962 review by Melzack and Wall of mechanisms underlying cutaneous sensibility. They argued against a fixed relationship between particular types of primary sensory neurons and sensory experience, endorsing in place a pattern arrangement. Three years later, Melzack and Wall (1965) proposed an imaginative theory for the neural mechanism of pain, which postulates a neural gate in the substantia gelatinosa of the spinal dorsal horn that controls the rostral projection of afferent messages evoking (see Figure 6). The proposal presumes the absence of specific sense organs for pain. Melzack and Wall gave special attention to the rarity of descriptions of peripheral afferents and central neurons with features consistent with those expected for nociceptors and nociception.

The gate-control theory accepts the presence of ascending pathways that carry activity related to pain. Messages carried by projection neurons in such an ascending system are 
presumed to be controlled by the neural gate in the spinal cord. The theory also presumes presynaptic modulation of primary afferent input to the projection neurons by cells of the substantia gelatinosa, which are themselves differentially influenced by activity in large- and small-diameter primary afferents. In the gate theory, the primary afferents, rather than being selectively responsive to stimuli, are presumed to differ in adaptation to maintained stimuli and in spontaneous (on-going) activity. The gate theory postulates that large-fiber afferent activity enhances presynaptic inhibition of the primary afferent input to the ascending projection neurons, thereby accommodating the established influence of innocuous mechanical stimulation on pain experience. Contrariwise, activity in small-diameter primary afferent fibers is presumed to facilitate activity of projection neurons. The proposal also considered control or modulation of spinal centers (substantia gelatinosa) by suprasegmental sources (i.e., central control of ascending activity), offering an explanation for the sometime absence of pain in the presence of severe tissue injury and mental stress.

The gate proposal caught the favor of clinicians faced with explaining aberrations in pain sensation that are inconsistent with a tight linkage between stimulus and reaction (pain). It also appealed to those concerned with modification of reactions by past or on-going events. Adding to its appeal, the postulated gate in the substantia gelatinosa could be structured to explain a variety of clinical symptoms and signs.

\section{Nociceptors}

An underlying assumption of the gate theory, the absence of sense organs specially adapted to signal pain-causing stimuli, was soon challenged. In 1967, Burgess and Perl showed that a substantial proportion of thinly myelinated afferent fibers in nerves supplying the cat skin are effectively excited only by strong (tissue-damaging) mechanical stimulation (Figure 7). These were considered nociceptive afferent fibers. They have distinctive receptive fields consisting of multiple spot-like regions from which responses could be evoked, separated by areas unresponsive to the effective stimulus (Burgess and Perl, 1967). Similar cutaneous "high-threshold" mechanoreceptors with myelinated fibers innervate primate skin (Perl, 1968; Campbell and Meyer, 1996). Later experiments established that such afferent units have unique spinal projections (Light and Perl, 1979; Figure 8). These A-fiber mechanical nociceptors typically have afferent fibers that conduct in the A $\delta$ range $(10-30 \mathrm{~m} / \mathrm{sec}$ in cat or monkey), although a number with the same phenotype are clearly $A \beta(30-50 \mathrm{~m} / \mathrm{sec}$ in cat or monkey). The spinal termination of this class of nociceptor has been established by intracellular labeling of functionally defined units (Light and Perl, 1979) to be in lamina I and laminae V/VI of the ipsilateral dorsal horn (e.g., Figure 8).

Other work established that a substantial proportion (50-90\%) of cutaneous C(unmyelinated) afferent fibers of rat, cat, monkey, and human are nociceptive, although differing in responsiveness from those with myelinated afferent fibers (Bessou and Perl, 1969; Kumazawa and Perl, 1978; Lynn and Carpenter, 1982; Torebjörk, 1974). The range of stimuli activating nociceptive sensory units varies according to the skin type (e.g., glabrous, hairy). A subset of C-fiber cutaneous nociceptors is excited by heat ( $>42-44$ degrees C) and some of this group are also responsive to acid and other irritants. It is important that many tissues are supplied by more than one phenotype of nociceptor. It is now established that skin is served by subsets of primary afferent units responsive to different kinds of strong stimulation (e.g., myelinated mechanical nociceptors, C-fiber heat-responsive nociceptors, myelinated heat and mechanical nociceptors). Nociceptive afferents have high thresholds to all stimuli prominent in nature and are especially adapted to respond to certain forms of intense stimuli. As a consequence, signals from nociceptors with different responsiveness underwrite differentiated transmission of information about noxious events (Belmonte and 
Cervero, 1996; Bessou and Perl, 1969; Kumazawa and Perl, 1978; Lynn and Carpenter, 1982; Price and Dubner, 1977; Torebjörk, 1974).

The cutaneous C-fiber nociceptors include a category called "polymodal nociceptors"; they are excited by heat, strong mechanical stimuli, and acid (Bessou and Perl, 1969). The response to heat and protons is mediated in part through activation of a unique cation membrane channel (VR-1/TRPV-1; Caterina et al., 1997). Similar specific sensitivities by other nociceptor categories impart to them a different responsiveness. Investigations in the period from the 1960s to the present brought compelling evidence not only for the existence of primary afferent units specially adapted to signal noxious events, but also for a molecular basis of certain responsive characteristics (Belmonte and Cervero, 1996; Julius and Basbaum, 2001; Dong et al., 2001; Zylka et al., 2003).

Proof of the existence of primary afferents with selective responsiveness to noxious stimuli was missing in the earlier explorations of somatic afferent signaling probably due to several circumstances. First, a majority of primary afferent nociceptors are small neurons with especially fine afferent fibers, making recording electrical signs of their activity difficult. Until the 1960s, electrophysiological recordings from single afferents were generally obtained by laboriously teasing fine filaments from a peripheral nerve with needles or sharp instruments (Iggo, 1960; Paintal, 1960). The time and labor involved in such work discouraged extensive surveys of the characteristics of thin primary afferents supplying particular tissues. A lack of enthusiasm for such work was especially evident in the scientific atmosphere of the 1950s and 1960s, with potent arguments against the concept of selectivity in afferent responsiveness advanced by prominent workers (Sinclair, 1952; Weddell, 1955; Melzack and Wall, 1962). To clarify this situation, a representative spectrum of signaling by primary afferents innervating a given tissue was needed.

This climate of strong opinions and uncertain evidence was the setting for the 1967 Burgess and Perl description of thin myelinated cutaneous afferents excited preferentially by noxious mechanical stimuli. In that study on cat, observations on a relatively large number of single myelinated afferents in given peripheral nerves were made possible by using a very fine glass pipette electrode to record action potentials from individual peripheral nerve fibers. The microelectrode technique permitted recording of discharges from a number of fine afferent fibers in each experiment. The results provided an overview of the myelinated afferent population of a peripheral nerve that documented a sizable percentage of primary sensory units selectively responsive to intense stimuli.

Once the existence of definable categories of nociceptive primary afferents was supported by convincing evidence, a wealth of work followed documenting and extending knowledge about "high-threshold" afferents (Bessou and Perl, 1969; Treede et al., 1990; Price and Dubner, 1977; Kumazawa and Perl, 1978; Koerber and Woodbury, 2002; Torebjörk, 1985; Torebjörk et al., 1984). Nociceptors are now established to be part of the afferent innervation of many tissues of mammals, with similar features in different species.

Importantly, many tissues are shown to have more than one type of nociceptor. The concept of sensory information from nociceptors currently has moved from the existence question to that of molecular specificities and activity-based changes (Julius and Basbaum, 2001).

\subsection{Nociceptor Sensitization}

Repeated identical innocuous stimulation of low-threshold somatic afferent receptors (e.g., mechanoreceptors) typically results in a stable or a progressive decrease of response. In contrast, nociceptors, particularly certain categories with unmyelinated afferent fibers, often exhibit enhancement of response on stimulus repetition (Bessou and Perl, 1969; Willis, 2006). Increased responsiveness of cutaneous afferents in the frog on repeated activation or 
injury was reported in 1937 to be a feature of slowly conducting afferent fibers (Echlin and Propper, 1937; also see Habgood, 1950). Such enhanced activation of primary afferents can represent a substantial increase in the signal presented to the CNS. An example is illustrated by Figure 9 (Kumazawa and Perl, 1977) for a primate C-fiber polymodal nociceptor on repeated exposure to noxious heat. It is important to note that sensitization of somatic nociceptors can be initiated by near-threshold stimuli (Figure 9).

Sensitization of nociceptors is an important feature of human response to noxious stimuli. Due to sensitization, threshold for evoking discharge from nociceptors can decrease from frankly noxious levels to innocuous intensities. Thus, it is held that nociceptor sensitization contributes to hyperalgesia after tissue injury (Campbell and Meyer, 2006; Hucho and Levine, 2007; Gold and Gebhart, 2010). Several mechanisms have been suggested for the production of sensitization and more than one process is involved (Jankowski et al., 2009). Nociceptor sensitization is promoted by excitatory action of molecular agents produced by tissue damage and inflammation (Jankowski et al., 2009). Chemical agents and molecular mediators associated with primary nociceptor sensitization range from cytokines involved in growth and development (e.g., nerve growth factor; Shu and Mendell, 1999) to products of arachidonic acid metabolism (e.g., prostaglandins, leukotrienes; Guerrero et al., 2008; Levine and Taiwo, 1990; Zeilhofer, 2007), vasoactive peptides (e.g., substance P, bradykinin; Couture et al., 2001; Cuello et al., 1977; Mantyh, 2002), and an acidic environment. Important features of sensitization are lowered threshold for evoking activity and a greater response to given intensities of stimuli than in the native state (Belmonte and Cervero, 1996; Bessou and Perl, 1969; Campbell and Meyer, 1996; Kumazawa and Perl, 1977).

\section{Spinal Control in Retrospect}

During the nearly one half century after its publication, the basic tenets of the gate-control theory have been subject to numerous tests. Many aspects of the gate hypothesis have proven inconsistent with experimental evidence. Among these is the fundamental supposition that "pain" receptors, sense organs with a features consistent with a dedicated function of signaling pain-producing stimulation, do not exist. It has become evident that clinical pain is a complex experience, in which the sensory aspect is only a part. Sherrington (1906) addressed the question of the sensory side by expressing the concept of noxious stimuli and tissue damage to define the relationship of afferent signaling of pain. The fact that selective high-threshold afferents are a regular part of tissue and organ innervation and serve effectively to indicate tissue damage renders a prime Melzack and Wall presumption invalid and damages their whole construct. Therefore, whereas the idea of "pain" sense organs is questionable, the concept of nociception and nociceptors is broadly established to be consistent with present evidence.

Another fundamental gate theory postulate, absence of central neurons selectively responsive to pain-causing stimuli, is also strongly challenged. Knowledge of characteristics of nociceptors made possible a directed search for central neurons receiving their activity. Christensen and Perl (1970) used characteristics of primary nociceptors to demonstrate that the spinal dorsal horn marginal zone (Rexed's lamina I) of cat contains neurons selectively excited by cutaneous nociceptors. Those observations were extended by subsequent work on experimental primates (Kumazawa and Perl, 1978; Light et al., 1979). Some lamina I neurons have axons ascending in the lateral white matter of the contralateral spinal cord (Foerster and Gagel, 1932; Kumazawa et al, 1975; Kuru, 1949).

The gate concept has been faulted for its proposal of a highly speculative functional organization in spinal lamina II (substantia gelatinosa). In question are postulates about 
presynaptic interactions between $\mathrm{C}$ - and myelinated fibers that do not fit experimental observations (Zimmermann, 1968). In fact, whether large-diameter primary afferent fibers receive or produce synaptic terminations in lamina II is uncertain (Hughes et al., 2003).

In contrast to the questionable facets, a noteworthy positive aspect of the gate control proposal is its invocation of descending control of spinal afferent transmission. The latter offers possible explanations for effects on nociception and pain expression by emotion, behavioral circumstances, and central nervous system dysfunction. Block or suppression of excitability of neurons forming part of an ascending projection could explain the absence of pain in cases of serious injury, such as battlefield wounds.

The gate arrangement also encouraged trial of novel therapies such as stimulation of the spinal dorsal columns to activate large-diameter primary afferents. Presumably this would close the gate and inhibit ascending activity from small-diameter afferents. Whereas some such manipulations have temporarily suppressed nociceptive reactions and/or pain, the mechanisms involved remain mysterious because the spinal cord stimuli used could engage a multitude of neural circuits (Guan et al., 2010; Linderoth and Meyerson, 2010; Meyerson and Linderoth, 2006). In sum, despite inconsistencies between concepts of the gate theory and experimental observation, it continues to attract clinicians' attention to account for variability between the nature and degree of peripheral injury and subjects' reports of pain. Putting the gate in a major central termination zone of C-fiber primary afferents has proven a stumbling block. Filters in pathways for reflex reactions and sensory activity could reside at several CNS levels. Moreover, presence of a variable filter (gate) in a circuit does not preclude dedication of neuronal systems to expressly transmit messages about noxious events.

\section{Ascending Pathways}

A crossed spinal pathway to the thalamus (spinothalamic; STT) was solidly established during the first half of the $20^{\text {th }}$ century. Nonetheless there are unsettled issues about its origins, terminations, and the nature of its relationships to pain. One uncertainty was the cellular source of the projecting axons. Until 1950 tools available for tracing long neural pathways were limited. For example, the Marchi technique, a method of classical histologists, labels myelinated axons that are disconnected from their cell bodies, but does not indicate unmyelinated fibers contributing to a tract. Clues about STT origins were provided by analyses of human chordotomy (cordotomy) cases. Separation of an axon from its cell body evokes retrograde changes in the histological appearance of the soma. Such changes were noted at post-mortem in cell bodies of the marginal zone of the contralateral spinal dorsal horn following the division of nerve fibers in the lateral column (Foerster and Gagel, 1932; Kuru, 1949). By comparing the segmental level of pain loss produced by chordotomy to the segmental distribution of retrograde changes in cells of the dorsal horn, Kuru (1949) concluded that part of the STT associated with pain originates from large Waldeyer-type neurons of the contralateral dorsal-horn marginal zone.

Cellular origins of the STT were also mapped by localized electrical stimulation of CNS fiber tracts to initiate antidromically conducted activity in the someas of projecting cells (Dilly et al., 1968). This technique was employed extensively by W.D. Willis's laboratory and others to identify the STT projection (Craig et al., 1994; Trevino et al., 1972a; 1973; Trevino et al., 1972b).

Retrograde axoplasmic transport of protein markers introduced in CNS locations is another form of histological evidence identifying cell somas contributing fibers to a tract and is logically complementary to pathway tracing by antidromically conducted impulses. The retrograde tracing procedure begins by injecting a foreign protein (e.g., horseradish 
peroxidase) into a region of projecting fibers from where it is transported by axoplasmic motors retrogradely to the cell body. The presence of the injected protein in projecting fibers can be visualized by histochemical reactions and/or fluorescence (Carstens and Trevino, 1978; LaVail and LaVail, 1972; Trevino and Carstens, 1975). The STT projecting fibers have been shown to originate from neurons located in several regions of the spinal cord. Initial studies in cat and rat of antidromic impulse or retrograde transport emphasized cells located in the base of the dorsal horn (Dilly et al., 1968; Trevino and Carstens, 1975; Trevino et al., 1972b). Later, in monkeys, the same techniques showed significant STT contributions also to come from neuronal cell bodies located in the contralateral superficial dorsal horn (Light, 1992; Trevino et al., 1973).

Interpretation of retrograde studies of neural pathways is complicated. Electrical stimulation of a CNS region can activate fibers of passage as well as those destined for the region in question. Another possibility is that not all projecting axons in a locus are activated by the stimulating-electrode pulse. Similarly, injection of tracer substances (horseradish peroxidase) can either be small in quantity, possibly labeling only part of the projecting population, or large and involve neurons belonging to adjacent systems.

On the basis of modern tract-tracing observations, the origin of the STT is complex, a complexity abetted by differences between species and by variation in data provided by different tracing techniques (Craig, 2003; Willis and Westlund, 1997). It is reasonably established that in primate, including humans, neurons contributing to the STT are located in the dorsal horn marginal zone (lamina I) and in the neck of the dorsal horn (laminae $\mathrm{V}$ through VI). (This location matches fairly closely to regions of terminal endings of "A $\delta$ " mechanical nociceptors of the skin.) In addition there appears to be a limited contribution from cells in the ventral horn and from neurons situated around the spinal central canal.

The STT axons passing rostrally in the ventrolateral spinal white matter form a major conduit for activity related to pain from disease or injury of the opposite side of the body (Foerster and Gagel, 1932; Spiller and Martin, 1912; White and Sweet, 1955). However, it is not the only pathway contributing to pain and nociceptive behaviors. For example, pain of visceral origin, particularly from the pelvic region, involves transmission by a spinal pathway in the dorsal columns near the midline (Willis et al., 1979; Willis and Westlund, 1997; King, 1977). There are other unresolved issues about ascending pathways and pain. For instance, what is the basis of the frequent recovery of pain-recognizing capacity some time after human ventrolateral chordotomy? Is the major factor enhanced excitability of connections in other pathways normally too weak to be effective? Or, are regeneration and new connections involved?

Electrophysiological studies have provided information on the kinds of peripheral stimuli activating STT neurons. Some lamina I neurons, activated antidromically from thalamic regions, respond only to noxious mechanical and/or heat stimuli. Others are more or less selectively excited by innocuous thermal stimuli (cooling or warming). Selectively responsive lamina I neurons have small, contralaterally located, and well defined receptive fields. They receive excitatory input from thinly myelinated or unmyelinated primary afferent fibers (Christensen and Perl, 1970; Craig, 2003; Kumazawa and Perl, 1978; Light, 1992). Some STT lamina I and deeper (laminae V-VI) spinal neurons have broader spectra of responsiveness. They are multimodal, responding modestly to innocuous mechanical stimuli and showing a notably greater response to noxious mechanical or heat stimuli. The multimodal STT neurons have been much studied and are considered by some commentators as a model for the STT system. Their frequent mention and focus in experimental work could be an artifact related to the ease of recording their activity compared to that of lamina I neurons. Lamina I neurons have limited dorsal-ventral dendritic 
extension, the usual trajectory of recording electrodes in in vivo electrophysiological explorations of the spinal cord. Therefore, signals of their activation are accessible in only a narrow dorsal-ventral zone. In contrast, dorsal horn neurons in deeper layers have more dendritic extension in the dorsal-ventral dimension and their electrical signals are more widely expressed, making their activity relatively easier to sample.

The multimodal neurons are commonly labeled "wide-dynamic range" (WDR), in reference to the range of their discharge frequencies to graded mechanical stimuli and their response to gentle mechanical stimulation as compared to that evoked by noxious heat (Mayer et al., 1975; Mendell, 1966; Price and Mayer, 1975). The receptive fields of the WDR-type cells are large relative to those of stimulus-selective lamina I neurons. It is argued that the selectively responsive lamina I STT neurons provide input used for discriminative recognition and localization of noxious and thermal stimuli, whereas the WDR neurons relate to emotional or behaviorally sensitive responses (Craig, 2003; Light, 1992; Willis and Westlund, 1997). On the other hand, some investigators propose that WDR neurons, with their broad range of responsiveness, have the capacity to signal the nature of the stimulus and contribute to localization. Other workers disagree (Craig, 2003; Light, 1992; Willis, 1985).

\section{Suprasegmental Projections}

\subsection{Medulla and Midbrain}

Tracing studies document that the ventrolateral spinal tract contains ascending fibers terminating in suprasegmental levels in addition to the thalamus. These include nuclei of the bulbar reticular formation, and the midbrain. Probably all are important for processing of signals related to somatic sensory events; however, the roles of projections to regions other than the thalamus are poorly understood. Further investigation is sorely needed.

Retrograde labeling indicates that an ascending fiber of the ventrolateral spinal tract may contribute to the both subthalamic and to thalamic terminations. Other data shows at least a partial independence in ventrolateral tract projections terminating in different loci (Willis and Westlund, 1997). Fibers in the lateral spinal white matter vary in their position in the tract as they ascend to their ultimate destination (Willis and Westlund, 1997). Fibers ending in the reticular region of the medulla originate from deep layers of the spinal dorsal horn or laminae VII and VIII of the ventral horn (Willis, 1985; Willis and Coggeshall, 1991). Several nuclei of the brain stem reticular region concerned with autonomic and visceral control are targets of ventrolateral spinal axons, including a prominent input to the parabrachial nuclei and locus coeruleus from spinal laminae I and V (Willis and Westlund, 1997).

\subsection{Thalamus and Cerebral Cortex}

Recognition of an event as noxious and painful involves the differentiation from other circumstances that affect tissue. If a somatic part of a mammal's body with intact nervous system is injured, the discomfort or sensation is referred to the damaged tissue and the intensity of the experience is usually in proportion to the tissue and the degree and extent of the damage. Pain in people and its apparent equivalent in other mammals has strong motivational and affective components. To explain nociception and pain, one needs to understand the mechanisms underlying each of these features - modality, reference location, emotional reaction, and subsequent behavioral outcomes. Insight into mechanisms responsible for different aspects of nociception and pain have been gained in recent years, albeit there is heated controversy about certain issues and how particular parts of the brain are involved. 
One fundamental issue is the nature and details of the spinothalamic projection to the thalamus and eventually to the cerebral cortex. The general outline is not in dispute. Ascending fibers from the ventrolateral spinal white matter reach the thalamic level and are distributed in two main groups. One set terminates laterally in or around the ventral posterior (ventrobasal) thalamus. A second set of fibers passes medially and is distributed to the intralaminar and central lateral thalamic nuclei. There is general agreement from morphological studies that some fibers of the STT pass through or terminate in the ventral posterior (ventrobasal) nuclei, the region receiving strong cutaneous and proprioceptivemechanoreceptive input from the medial lemniscus (Jones, 1985). On the other hand, how the spinothalamic and medial lemniscus projections interrelate is uncertain. In conscious human subjects, electrical stimulation of the ventrobasal tactile receptive zone during neurosurgical procedures sometimes does and sometimes does not evoke pain-like sensations. Electrical stimuli delivered to sites adjacent to cellular zones evincing tactile responsiveness is reported to evoke pain referred to the contralateral body. Such stimuli on occasion have been reported to reproduce a pain previously experienced by the subject (Halliday and Logue, 1972; Lenz et al., 1994; Lenz et al., 1993a; Lenz et al., 1993b; Price and Dubner, 1977). Both selectively nociceptive and WDR categories of neurons have been described in the ventrobasal thalamic region. Interestingly, Kenshalo et al. (2000) noted that in the primate ventrobasal region of the thalamus nociceptive neurons were found surrounded by tactile-receptive cells. Similar arrangements have been reported in cat VPL (Honda et al., 1983). Whether these two classes are intermingled with the tactile responsive neurons or adjacent to them remains uncertain (Dostrovsky, 2000; Halliday and Logue, 1972; Hassler, 1960; Honda et al., 1983).

The STT component of the crossed ventrolateral spinal pathway reaches its most rostral level in thalamic terminations, however, the thalamus and cerebral cortex are intimately related and connected. A number of the thalamic nuclei represent way-stations in projections to particular cortical regions. Some thalamic nuclei are so closely related to a cerebral cortical region as to being considered cortical dependencies because lesion of the cortical area leads to retrograde degeneration of the related thalamic somas (Jones, 1985; Jones, 2007). The strong cortical projections of thalamic nuclei receiving STT input indicate that the latter's activity is destined to influence cortical functions. Just how is unknown. In fact, the nature of STT information conveyed to the thalamus and what in turn is transmitted to the cerebral cortex is also only partially established (Craig, 2003; Dostrovsky, 2000; Halliday and Logue, 1972; Hassler, 1960; Honda et al., 1983).

Whereas the basic connections between the thalamus and the cerebral cortex have been provided by morphological analyses (Jones, 1985; Jones, 2007), significant additions recently have emerged from studies imaging activity in human and lower animal brains in vivo. To date, the most notable advances have come from approaches based on detection of changes in blood flow or tissue fluid by positive emission tomography (PET) or functional magnetic resonance imaging (fMRI; Davis et al., 1997; Hofbauer et al., 2001; Jones et al., 2003; May, 2007; Peyron et al., 2000). Changes in blood flow or tissue fluid presumably reflect activity of neurons or glial cells in the vicinity due to the accumulation of metabolites and changes in ion concentration. Imaging techniques dependent upon electrical or magnetic signs (magnetoencephalography, MEG; electroencephalography, EEG) as yet have contributed fewer insights, partially due to limits imposed by their limited spatial resolution and the weakness of their signals.

Using pain-causing stimulation to evoke responses in conscious humans, PET and fMRI studies have established that a given stimulus activates multiple cerebral cortical regions. Cortical regions showing pain-related activity include the contralateral somatosensory I, somatosensory II, and, consistently, the anterior cingulate cortex (ACC). Whole-brain 
imaging has the advantage of simultaneous measurements of multiple areas. The results strongly point to complex and distributed processing. The present data hints of parallel appearance of activity related to pain, but better temporal resolution is necessary to determine whether the parallel appearances of the increased activity in separate cortical sites represents true parallel processing. Thus, though time and signal resolution of PET and fMRI imaging currently are limited, these new approaches provide novel information on the location and operation of neural mechanisms in the brain underwriting sensation (Davis $e t$ al., 1997; Hofbauer et al., 2001; Jones et al., 2003; May, 2007; Peyron et al., 2000).

Anatomical studies that first defined the thalamic target of the STT describe terminations in the ventrobasal region, more or less overlapping projection fibers of the medial lemniscus (Foerster and Gagel, 1932; Walker, 1938). Information about the terminations of the spinal projection to the thalamus greatly expanded with the improvement of pathway tracing techniques. In 1960 Mehler, Feferman, and Nauta, using the then new Nauta silver technique of labeling anterograde degeneration, showed the ventral lateral spinal tract to terminate not only in the thalamic ventrobasal region, but also more caudally in the posterior nuclear (PO) zone and medially in the thalamic parafascicular and central lateral nuclei (Mehler et al., 1960; Willis and Westlund, 1997).

Craig and coworkers report a major termination of ascending fibers from spinal lamina I in the posterior part of the ventral-medial (VMpo) nucleus. The lamina I projection to VMpo is reported to be nociceptive-specific or thermal-specific, with small peripheral receptive zones (Craig et al., 1994). The lamina I projection to VMpo differs from the reported somatotopic, stimulus-specific STT termination in the ventrobasal thalamus. How the somatotopic arrangement of the spinothalamic projection to the ventrobasal thalamus relates to VMpo has yet to be established.

The features of VMpo are controversial. Craig's group describes the spinal lamina I projection to VMpo to be distinguished by calbindin-reactive fibers (Blomqvist et al., 2000), a characterization that is vigorously questioned (Graziano and Jones, 2004; Willis et al., 2002; but see Craig and Blomqvist, 2002). The immunohistochemical evidence for the calbindin localization has been questioned (Graziano and Jones, 2004).

Initially in the $20^{\text {th }}$ century the thalamus was considered the rostral brain center important for the elaboration of pain. This attribution derived from clinical studies of the thalamic syndrome, in which pathological pain is a prominent symptom (Déjerine and Roussy, 1906; Head, 1920; Head and Holmes, 1911). A thalamic rather than cerebral cortical locus for expression of pain was supported by early observations from electrical stimulation of exposed cerebral cortices in awake human subjects. Evocation of pain by cortical stimulation was very rarely noted, although generation of other somatosensory experiences were routine (Penfield and Boldrey, 1937). In contrast, the relevance of the thalamus to pain is emphasized by both recording and stimulation experiments on human subjects (Halliday and Logue, 1972; Lenz et al., 1994; Lenz et al., 1993a; Lenz et al., 1993b). Selective, somatotopically experienced pain is reported to be evoked by localized stimulation of the human lateral thalamus adjacent to the tactile region.

Evidence for a selectively nociceptive projection to the ventral posterior thalamus is incomplete. Several experimental animal studies suggest that a region intercalated with or adjacent to the somatotopically detailed mechanoreceptive projection to the ventrobasal nuclei receives a specific nociceptive input (Casey and Morrow, 1983; Gaze and Gordon, 1954; Honda et al., 1983; Kenshalo et al., 1980; Perl and Whitlock, 1961). Data supporting a layered or intertwined arrangement comes from stereotaxic electrophysiological explorations of the ventrobasal thalamus. Small movements of a recording electrode produce 
sequential changes of receptive fields and effective stimuli. For example, in cat the most dorsal cells encountered on dorsal entry to the ventrobasal nuclei are selectively nociceptive while more ventrally the recordings feature activity evoked by innocuous mechanical stimuli (Honda et al., 1983).

Understanding of the cortical connections of thalamic nuclei receiving spinothalamic input is partially mired in the controversy over the parts played by the ventrobasal region of the lateral thalamus and the recently defined VMpo. The ventrobasal nuclei with their stimulusselectivity and somatotopic arrangement project heavily to the somatosensory I (SI) zone of the parietal cortex. However, electrophysiological documentation of nociceptive neuronal activity in SI is limited (Kenshalo and Isensee, 1983; Kenshalo et al., 2000; Treede et al., 2000). Some workers attribute to a lateral SST projection, information necessary for recognition and localization of noxious peripheral events. In this postulate, medial thalamic projections of the STT serve different functions, contributing to affective, motivational, and autonomic activities. The medial STT projections to the parafascicular and central lateral nuclei are presumed to relate to parts of the ACC. In the VMpo construct, by contrast, the main cortical target of the nociceptive-specific STT projection is the anterior insular cortex rather than SI of the parietal lobe.

Prior to the advent of imaging brain activity, information on participation of the cerebral cortex in pain and nociceptive reactions came from the effects of cortical lesions and electrophysiological recordings from individual neurons in experimental primates. Clinical case descriptions indicate that relatively large lesions of the human cerebral cortex, including those involving the parietal region, do not eliminate the capacity to recognize painful stimuli (e.g., Russell, 1945). On the other hand, analyses of restricted lesions of the human cerebral cortex, conclude that localized, selective, contralateral loss of pain perception is produced by limited lesions of the posterior parietal area near the central sulcus (Déjerine and Mouzon, 1915; Kleist, 1934; Marshall, 1951; Russell, 1945).

Electrophysiological studies in primates report that certain neurons in the cortex of the central sulcus (SI; Brodman's Area 3) have selective nociceptive characteristics (Kenshalo and Isensee, 1983; Kenshalo et al., 2000; Kenshalo et al., 1988; Kenshalo and Willis, 1991). It is tempting to relate the deficits in pain appreciation produced by circumscribed human cortical lesions to the observations on primate electrophysiology. It may be relevant that Brodman's Area 3a, a zone identified as containing selective nociceptive neurons, lies partially in the central sulcus, a position that would make activity of its neurons relatively difficult to sample.

\section{Recapitulation}

By the end of the $20^{\text {th }}$ century the concept of nociception and the existence of primary afferent nociceptors had become widely accepted. Distinctive primary afferent neurons that signal noxious events by selective activity are shown to innervate most body tissues. Neural pathways from the detecting elements to higher centers are documented, although the nature of convergence of nociceptive and low-threshold afferents in these pathways remains debated. It has also become clear that the pathways transmitting pain-related information from the periphery are flexible and subject to change as a consequence of modulation by local or descending control systems. Activity-dependent alterations are evident at nociceptors' peripheral receptive terminals and central synapses. It is now more broadly appreciated that input from nociceptive afferents serve functions other than sensation (see Belmonte and Cervero, 1996). Afferent, local, and descending modulatory factors are understood to be capable of altering the nature of signals about injury or to abet disordered function. Finally, brain-activity imaging studies seem to suggest the experience of pain to involve parallel processing by different cerebral (cortical) regions. 


\section{Comment on Current Issues}

\subsection{Neuropathic Pain}

The term "neuropathic" is used to describe certain categories of pain symptoms and processing. Common usage defines neuropathic pain as "initiated or caused by primary lesion or dysfunction in the nervous system" (International Association for the Study of Pain, 2011). The damaged tissue may be peripheral nerve, nerve roots, or central nervous system structures. This definition distinguishes pain originating from peripheral or central nervous system dysfunction from pain initiated or maintained by injury or disease of other tissues or organs. In this logic, pain appearing in association with injury of non-neural tissue can be referred to as nociceptive pain. It is important to note that nociceptive pain under certain conditions can evolve into a neuropathic disorder. Pain of nervous system origin typically starts with an injury or other pathology affecting a neural structure. Therefore, neuropathic pain differs from normal nociception in that the experience is not the direct outcome of the signaling of injury of peripheral tissue or organs.

There is an unfortunate history in the literature on neuropathic pain. The implication from reports particularly devoted to testing of pharmacological agents or manipulations of neural activity is that different experimental models (e.g., Bennett and Xie, 1988; Kim and Chung, 1992; Seltzer et al., 1990; Wang and Wang, 2003), especially those based upon alterations of peripheral afferents, evaluate equivalent processes and actions. Whereas there may be common ground to the various experimental models of peripheral neuropathy, the differences in procedure, ranging from partial lesion of mixed peripheral nerve to deafferentation of adjacent segments of the spinal cord, suggest differences in inherent processes must be considered.

\subsection{Chronic Pain}

"Chronic" implies "persisting." The term "chronic pain" is widely used in clinical situations and elsewhere to label lasting or repeated pain regardless of origin, as if there is common ground for types originating from different causes. The latter concept implies persisting pain has special properties and unique mechanisms. As mentioned above, persisting neural activity has both theoretical and proven capacity to initiate processes modifying functional neural connections and the excitability of neural circuits. Nevertheless, certain clinical pains are long lasting because the initiating disease or damage persists and is responsible for ongoing activation of nociceptors and their projections (Gold and Gebhart, 2010). Thus, certain classes of "chronic pain" can result from continuation of circumstances activating mechanisms mimicking those of acutely produced nociceptive pain. On the other hand, pain of central neural origin often is persisting and results from processes at least partially differing from those directly triggered by tissue injury (see Boivie, 2006; Finnerup, 2008). Persisting pain of nociceptive origin has therapeutic prospects different from those related to neuropathic pain and therefore needs to be distinguished in clinical situations.

\subsection{Central Sensitization and Central Pain}

It is notable that many situations fitting the definition of central neuropathic pain represent partial disruption of the normal nociceptive and pain neural apparatuses. From this standpoint, central pain is one expression of neuropathy. Is there common ground for painful peripheral neuropathy and central pain? Possibly. Neurons in part of sensory systems in the mammal typically have a center-surround or adjacent region distribution of excitatory and inhibitory receptive fields (Mountcastle and Powell, 1959; Hartline, 1967). Injury or lesion of either peripheral or central pathways carrying noxious information will remove part of that pattern of innervation. If the deficit is biased to the inhibitory part of the arrangement, an unbalanced situation with limited inhibition could present. One can speculate that the 
common ground of neuropathic pain represents an unbalanced loss of inhibition in a part of the ascending projection system for nociceptive information. Animal models of peripheral neuropathic pain have in common deliberate partial denervation by transection or partial ligation of spinal nerves or roots (e.g., Bennett and Xie, 1988; Kim and Chung, 1992; Seltzer et al., 1990; reviewed in Wang and Wang, 2003). Obviously there is more to the processes leading to neuropathic pain than simply a loss of inhibitory interactions between afferent signals. For example, the nerve injury involved in neuropathic models may alter the excitability of afferent neurons so that they generate spontaneous activity easily. Similarly, in CNS pathology the disruption of functional organization may limit inhibitory interactions and result in unbalanced bias toward excitation and activation of neuronal systems producing pain experience by inputs too weak in intact systems to reach threshold.

When the nervous system is intact, nociception and pain share mechanisms. After injury of the peripheral or central nervous system, separation (dissociation) can occur between nociceptive mechanisms that prevent or limit further injury of tissue and the experience of pain. Pain secondary to disorders of the central nervous system (central pain) typically is persisting, especially unpleasant, and resistant to therapy (Boivie, 2006; Finnerup, 2008; Latremoliere and Woolf, 2009). It frequently appears as a consequence of injury or other pathology of the STT pathway or its thalamic targets (Cassinari and Pagni, 1969; Pagni, 1998). Central pain does not have a peripheral afferent origin and therefore does not represent nociception. On the other hand, its mechanisms may involve neurons and systems that are part of the apparatus for nociception. Frequent manifestation of central pain after injury of the STT also is consistent with the possibility that it reflects loss of inhibitory interactions. One mechanism would have neurons in STT projection pathway participate in mutual inhibition of a type operating in "surround" patterns.

Central sensitization, enhanced response (activation) of a neuronal network or pathway to afferent input is now invoked to explain increased reaction to peripheral stimulation (Kuner, 2010; Latremoliere and Woolf, 2009). Multiple processes are probably involved and are presumed to interact (Kuner, 2010). One reasonable postulate is that mechanisms of central sensitization and central pain are operationally related (Latremoliere and Woolf, 2009).

\subsection{Sensation vs. Emotion}

The most compelling evidence that pain represents an independent sensation comes from the sometime dissociation of nociceptive pain from the ability to perceive tactile, thermal, or proprioceptive experiences. Injury or pathology has been noted to eliminate some somatic tactile sensation in regions that have intact pain experience or the converse. Division of STT projections into lateral and medial thalamic distributions with different connections to different cerebral cortical areas is also consistent with dissociation of pain from other sensations and of different aspects of the pain experience. As described earlier, the lateral thalamic STT termination is argued to carry modality- and place-specific information suitable for discrimination and localization, whereas the medial STT thalamic projection is proposed to have a more convergent composition and target. Division of thalamic termination is also reflected in differential activation of cerebral cortex regions by painful and nonpainful stimulation. Among other considerations, selective activation of anterior cingulate cortical (ACC) regions in imaging experiments, i.e., according to whether the task has discriminative or affective implications (Davis et al., 1997; Vogt et al., 1993), has prompted a resurgence of the idea of pain as an emotion. It is relevant in this regard that several lines of evidence link the ACC to processing of emotionally related stimuli (Devinsky et al., 1995; Yoshino et al., 2010).

Craig (2003) has revived the idea that pain is a homeostatic emotion, a concept proposed by Darwin (1872). Unhappily, pain does not readily fit the dimensions of homeostasis. The 
emotion idea may be more tenable. Noxious stimuli and experienced pain usually are related to notable changes in blood pressure, heart rate, and respiration that appear inconsistent with the concept of homeostasis (Cannon, 1932). If pain is an emotion, why can it dissociate from tactile and proprioceptive sensory experiences after injuries of peripheral nerve? However, pain does have unusual capability to evoke discomfort and negative affective reactions. It seems reasonable to consider that pain represents both a sensation that underlies discrimination of the nature of tissue-damaging events and a partially independent emotion that activates motivational behavior. Is it possible to come full circle from Aristotle and Darwin, who - while categorizing pain as an emotion - recognized that sensory experiences from events affecting the body are essential for the maintenance of life? Without the latter, an animal or person could not determine when it suffers injury and would lack place information to react to prevent further damage. Does separation of processes for sensation and affect reflect the separation of the lateral-medial thalamic projections and independence in thalamic-mediated inputs to the cerebral cortex? Is there parallel processing of information for discrimination of pain location and type and that leading to affective behavior? It is interesting to speculate that such separation of processing would permit dissociation between the relative amplitudes of sensory experience and emotional reaction. Such a dissociation is a common experience in human clinical pain.

\section{Other Important Issues}

Insight on pain and its mechanisms has increased appreciably since 1950. Nevertheless, understanding of basic processes and pathologies is still incomplete. A fundamental issue is whether upon tissue injury the neural system generating an experience named "pain" is mediated and produced by a dedicated, selective arrangement or has a quantitatively related pattern basis. Experimental evidence favors the existence of both organizational features in pathways and regions of the brain active in nociceptive pain (Light, 1992; Willis and Westlund, 1997). It appears reasonable to propose both 1) specific dedicated mechanisms for nociception, providing information for discrimination and localization, and 2) a convergent, quantitatively based system related to intensity of perception and to initiation of emotional and motivational reactions.

What are the roles of glia in situations related to chronic and neuropathic pain? In particular, how do non-neural cells such as microglia and astrocytes fit into the pathology of pain? There is mounting evidence of changes in functions of glia and aberrations of pain expression (reviewed in Graeber, 2010; O'Callaghan and Miller, 2010; Ren and Dubner, 2010). Invocation of possible glial contributions to persisting pain and its pathology raises the question of the relationship of glia to the immune system (see Austin and MoalemTaylor, 2010).

Distinctive characteristics of the nociceptors that innervate a tissue or an organ provide capability of signaling the nature of a noxious event; however, the bases of such selective responsiveness are only known in a few instances. In other words, the molecular structures providing stimulus selectivity and those associated with alterations in responsiveness of primary afferent neurons are at the dawn of discovery (Basbaum et al., 2009). The lack of knowledge hinders rational therapy for undesirable pain. Furthermore, the spectrum of changes in the central nervous system associated with prolonged activity of nociceptors remains unclear. Thus, peripheral and central sensitization are issues that need to be more fully explored.

The intimate neuronal activity in processes leading to pain is also largely unknown. General projection pathways and a global idea of connections are understood, but how individual or populations of neurons generate the perceptual experience of pain are a mystery. New tools 
for imaging neural activity in the intact or the partially intact brain provide some novel insights. The ability to monitor activity of neurons without disrupting the system opens doors to establishing integrative arrangements. Genetic methodologies have the potential for marking, exciting, increasing, or deleting specific neurons or neurons of a particular class. Those capabilities will certainly be harnessed to imaging to further establish interactions and their implications. In addition to unknowns about relationships of the activity of individual central neurons to that of populations in a perceptual experience, the significance of parallel activities in widely different neuronal groups in reference to pain remains to be uncovered.

The neural basis of perception remains a mystery. What translations take place in signals representing features of the environment to conscious recognition and definition? Where does this translation occur? The shared ignorance of the basis of sensory perception has implications for understanding pathologies of pain. Is pain pathology -- that is, one or another form of neuropathic pain -- sometimes related to broad shifts in neuronal excitability, or growth of new connections, or selective loss of inhibition? When persisting nociceptor inputs or neural lesions lead to aberrant pain, are novel connections and interactions formed or is the fundamental pathology the loss of integrated function?

\section{Acknowledgments}

I thank Bonnie Taylor-Blake for her considerable work and help on the bibliography and preparation of the manuscript. Support for the preparation of this article was provided by a grant from the National Institutes of Health (NS10321).

\section{Abbreviations}

$\begin{array}{ll}\text { fMRI } & \text { Functional magnetic resonance imaging } \\ \text { PAG } & \text { Periacqueductal grey } \\ \text { PET } & \text { Positive emission tomography } \\ \text { STT } & \text { Spinothalamic tract } \\ \text { WDR } & \text { Wide dynamic range } \\ \text { VMpo } & \text { Posterior part of the ventral medial nucleus of the thalamus } \\ \text { VR-1/TRPV-1 } & \text { Vanoillid receptor / Transient receptor potential cation channel, } \\ & \text { subfamily V, member 1 }\end{array}$

\section{References}

Adrian ED. The impulses produced by sensory nerve-endings. Part 4. Impulses from pain receptors. J. Physiol. 1926a; 62:33-51. [PubMed: 16993827]

Adrian ED. The impulses produced by sensory nerve endings. Part I. J. Physiol. 1926b; 61:49-72. [PubMed: 16993776]

Adrian ED, Bronk DW. The discharge of impulses in motor nerve fibres. Part I. Impulses in single fibres of the phrenic nerve. J. Physiol. 1928; 66:81-101. [PubMed: 16993976]

Adrian ED, Zotterman Y. The impulses produced by sensory nerve endings. Part 2 . The response of a single end-organ. J. Physiol. 1926; 61:151-171. [PubMed: 16993780]

Adrian ED, Cattell M, Hoagland H. Sensory discharges in single cutaneous nerve fibres. J. Physiol. 1931; 72:377-391. [PubMed: 16994216]

Austin PJ, Moalem-Taylor G. The neuro-immune balance in neuropathic pain: Involvement of inflammatory immune cells, immune-like glial cells and cytokines. J. Neuroimmunol. 2010; 229:26-50. [PubMed: 20870295] 
Basbaum AI, Bautista DM, Scherrer G, Julius D. Cellular and molecular mechanisms of pain. Cell. 2009; 139:267-284. [PubMed: 19837031]

Bayliss WM. Further researches on antidromic nerve-impulses. J. Physiol. 1902; 28:276-299. [PubMed: 16992622]

Beecher, HK. Measurement of Subjective Responses: Quantitative Effects of Drugs. Oxford University Press; New York: 1959. Reaction Factors of the Pain Experience; p. 162-166.

Bell, C. Idea of a New Anatomy of the Brain; Submitted for the Observations of His Friends. Strahan and Preston; London: 1811.

Belmonte, C.; Cervero, F. Neurobiology of Nociceptors. Oxford University Press; Oxford: 1996.

Bennett GJ, Xie YK. A peripheral mononeuropathy in rat that produces disorders of pain sensation like those seen in man. Pain. 1988; 33:87-107. [PubMed: 2837713]

Bessou P, Laporte Y. Étude des récepteurs musculaires innervés par les fibres afférentes du groupe III (fibres myelinisées fines) chez le chat. Arch. Ital. Biol. 1961; 99:293-321.

Bessou P, Perl ER. Response of cutaneous sensory units with unmyelinated fibers to noxious stimuli. J. Neurophysiol. 1969; 32:1025-1043. [PubMed: 5347705]

Bishop GH, Heinbecker P, O'Leary JL. The function of the non-myelinated fibers of the dorsal roots. Am. J. Physiol. 1933; 106:647-669.

Blix M. Experimentelle Beiträge zur Lösung der Frage über die specifische Energie der Hautnerven. Z. Biol. 1884; 20:141-156.

Blomqvist A, Zhang ET, Craig AD. Cytoarchitectonic and immunohistochemical characterization of a specific pain and temperature relay, the posterior portion of the ventral medial nucleus, in the human thalamus. Brain. 2000; 123:601-619. [PubMed: 10686182]

Boivie, J. Central pain. In: McMahon, SB.; Koltzenburg, M., editors. Wall and Melzack's Textbook of Pain. Elsevier; London: 2006. p. 1057-1074.

Brown-Séquard, CE. Course of Lectures on the Physiology and Pathology of the Central Nervous System. Collins; Philadelphia: 1860.

Brown-Séquard CE. Lectures on the physiology and pathology of the nervous system; and on the treatment of organic nervous affections. Lancet. 1868; 2:593-596.

Burgess PR, Perl ER. Myelinated afferent fibres responding specifically to noxious stimulation of the skin. J. Physiol. 1967; 190:541-562. [PubMed: 6051786]

Campbell, JN.; Meyer, RA. Cutaneous nociceptors. In: Belmonte, C.; Cervero, F., editors. Neurobiology of Nociceptors. Oxford University Press; Oxford: 1996. p. 117-145.

Campbell JN, Meyer RA. Mechanisms of neuropathic pain. Neuron. 2006; 52:77-92. [PubMed: 17015228]

Cannon, WB. The Wisdom of the Body. W.W. Norton; New York: 1932.

Carstens E, Trevino DL. Laminar origins of spinothalamic projections in the cat as determined by the retrograde transport of horseradish peroxidase. J. Comp. Neurol. 1978; 182:151-165.

Casey KL, Morrow TJ. Ventral posterior thalamic neurons differentially responsive to noxious stimulation in the awake monkey. Science. 1983; 221:675-677. [PubMed: 6867738]

Cassinari, V.; Pagni, CA. Central Pain: A Neurosurgical Survey. Harvard University Press; Cambridge: 1969.

Caterina MJ, Schumacher MA, Tominaga M, Rosen TA, Levine JD, Julius D. The capsaicin receptor: a heat-activated ion channel in the pain pathway. Nature. 1997; 389:816-824. [PubMed: 9349813]

Charcot, JM. Lectures on the Diseases of the Spinal Cord (translated). Young J. Pentland; Edinburgh: 1881.

Christensen BN, Perl ER. Spinal neurons specifically excited by noxious or thermal stimuli: Marginal zone of the dorsal horn. J. Neurophysiol. 1970; 33:293-307. [PubMed: 5415075]

Clark D, Hughes J, Gasser HS. Afferent function in the group of nerve fibers of slowest conduction velocity. Am. J. Physiol. 1935; 114:69-76.

Couture R, Harrisson M, Vianna RM, Cloutier F. Kinin receptors in pain and inflammation. Eur. J. Pharmacol. 2001; 429:161-176. [PubMed: 11698039]

Craig AD. Pain mechanisms: labeled lines versus convergence in central processing. Annu. Rev. Neurosci. 2003; 26:1-30. [PubMed: 12651967] 
Craig AD, Blomqvist A. Is there a specific lamina I spinothalamocortical pathway for pain and temperature sensations in primates? J. Pain. 2002; 3:95-101. [PubMed: 14622793]

Craig AD, Bushnell MC, Zhang ET, Blomqvist A. A thalamic nucleus specific for pain and temperature sensation. Nature. 1994; 372:770-773. [PubMed: 7695716]

Cranefield, PF. The Way In and the Way Out: François Magendie, Charles Bell and the Roots of the Spinal Nerves. Futura Publishing Company; Mount Kisco, NY: 1974.

Cuello AC, Jessell TM, Kanazawa I, Iversen LL. Substance P: localization in synaptic vesicles in rat central nervous system. J. Neurochem. 1977; 29:747-751. [PubMed: 591950]

Dallenbach KM. Pain: History and present status. Am. J. Psychol. 1939; 52:331-347.

Darwin, C. The Expression of the Emotions in Man and Animals. Murray, J.; London: 1872.

Davis KD, Taylor SJ, Crawley AP, Wood ML, Mikulis DJ. Functional MRI of pain- and attentionrelated activations in the human cingulate cortex. J. Neurophysiol. 1997; 77:3370-3380. [PubMed: 9212281]

Déjerine J, Mouzon J. Un nouveau type de syndrome sensitif cortical observé dans un cas de monoplégie corticale dissociés. Rev. Neurol. 1915; 18:1265-1273.

Déjerine J, Roussy G. Le syndrome thalamique. Rev. Neurol. 1906; 14:521-532.

Devinsky O, Morrell MJ, Vogt BA. Contributions of anterior cingulate cortex to behavior. Brain. 1995; 118:270-306.

Dilly PN, Wall PD, Webster KE. Cells of origin of the spinothalamic tract in the cat and rat. Exp. Neurol. 1968; 21:550-562. [PubMed: 5677267]

Dong X, Han S, Zylka MJ, Simon MI, Anderson DJ. A diverse family of GPCRs expressed in specific subsets of nociceptive sensory neurons. Cell. 2001; 106:619-632. [PubMed: 11551509]

Dostrovsky, JO. Role of Thalamus in Pain. In: Sandkühler, J.; Bromm, B.; Gebhart, GF., editors. Nervous System Plasticity and Chronic Pain. Elsevier; Amsterdam: 2000. p. 245-258.

Du Bois-Reymond, E. Untersuchungen über thierische Elektricität. Georg Reimer; Berlin: 1848-1849.

Eccles RM, Lundberg A. Supraspinal control of interneurones mediating spinal reflexes. J. Physiol. 1959; 147:565-584. [PubMed: 13819185]

Echlin F, Propper N. "Sensitization" by injury of the cutaneous nerve endings in the frog. J. Physiol. 1937; 88:388-400. [PubMed: 16994832]

Edinger L. Einigles von Verlauf der Gefühlsbahnen in centralen Nervensysteme. Deutsche Med. Woch. 1890; 16:421-426.

Edinger, L. Zwölf Vorlesungen über den Bau der Nervösen Centralorgane. Für Ärzte und Studirende. F.C.W. Vogel; Leipzig: 1892.

Erb, W. Handbuch der Krankheiten des Nervensystems II. F.C.W. Vogel; Leipzig: 1874.

Erlanger J, Gasser HS, Bishop GH. The compound nature of the action current of nerve as disclosed by the cathode ray oscillograph. Am. J. Physiol. 1924; 70:624-666.

Fields HL, Basbaum AI, Clanton CH, Anderson SD. Nucleus raphe magnus inhibition of spinal cord dorsal horn neurons. Brain Res. 1977; 126:441-453. [PubMed: 861731]

Fields HL, Vanegas H, Hentall ID, Zorman G. Evidence that disinhibition of brain stem neurones contributes to morphine analgesia. Nature. 1983; 306:684-6. [PubMed: 6656868]

Finnerup NB. A review of central neuropathic pain states. Curr. Opin. Anesthesiol. 2008; 21:586-589.

Foerster O, Gagel O. Die Vorderseitenstrangdurchschneidung beim Menschen. Eine klinisch-pathophysiologische-anatomische Studie. Z. ges. Neurol. Psychiat. 1932; 138:1-92.

Foster, M.; Sherrington, CS. A Textbook of Physiology. Macmillan; London: 1897.

Frey, M. v. Beiträge zur Physiologie des Schmerzsinns. Königl. Sächs. Ges. Wiss., Math.- Phys. Classe. 1894; 46:185-196.

Frey, M. v. Beiträge zur Sinnesphysiologie der Haut. Dritte Mittheilung. Königl. Sächs. Ges. Wiss., Math.-Phys. Classe. 1895; 47:166-184.

Frey, M. v. Untersuchungen über der Sinnesfunctionen der Menschlichen Haut. Erste Ablandlung: Druckempfindung und Schmerz. Königl. Sächs. Ges. Wiss., Math.-Phys. Classe. 1896; 48:175266. 
Fulton, JF. Muscular Contraction and the Reflex Control of Movement. The Williams \& Wilkins Company; Baltimore: 1926.

Gasser HS. Properties of dorsal root unmedullated fibers on the two sides of the ganglion. J. Gen. Physiol. 1955; 38:709-728. [PubMed: 14367780]

Gasser HS, Erlanger J. A study of the action currents of nerve with the cathode ray oscillograph. Am. J. Physiol. 1922; 62:496-524.

Gaze RM, Gordon G. The representation of cutaneous sense in the thalamus of the cat and monkey. Q. J. Exp. Physiol. 1954; 39:279-304.

Gold MS, Gebhart GF. Nociceptor sensitization in pain pathogenesis. Nat. Med. 2010; 16:1248-1257. [PubMed: 20948530]

Goldscheider A. Die specifische Energie der Gefühlsnerven der Haut. Monatshft. Prak. Derm. 1884; $3: 283$.

Golgi, C. Sulla fina anatomia degli organi centrali del sistema nervoso. S. Calderini; Reggio-Emilia: 1885.

Gowers WR. A case of unilateral gunshot injury to the spinal cord. Trans. Clin. Soc. Lond. 1878; $11: 24-32$.

Graeber MB. Changing face of microglia. Science. 2010; 330:783-788. [PubMed: 21051630]

Graziano A, Jones EG. Widespread thalamic terminations of fibers arising in the superficial medullary dorsal horn of monkeys and their relation to calbindin immunoreactivity. J. Neurosci. 2004; 24:248-56. [PubMed: 14715957]

Gruner, OC. A Treatise on the Canon of Medicine of Avicenna, Incorporating a Translation of the First Book. Luzac \& Co.; London: 1930.

Guan Y, Wacnik PW, Yang F, Carteret AF, Chung C-Y, Meyer RA, Raja SN. Spinal cord stimulationinduced analgesia: clectrical stimulation of dorsal column and dorsal roots attenuates dorsal horn neuronal excitability in neuropathic rats. Anesthesiology. 2010; 113:1392-1405. [PubMed: 21068658]

Guerrero AT, Verri WA Jr. Cunha TM, Silva TA, Schivo IR, Dal-Secco D, Canetti C, Rocha FA, Parada CA, Cunha FQ, Ferreira SH. Involvement of LTB4 in zymosan-induced joint nociception in mice: participation of neutrophils and PGE2. J. Leukoc. Biol. 2008; 83:122-130. [PubMed: 17913976]

Habgood JS. Sensitization of sensory receptors in the frog's skin. J. Physiol. 1950; 3:195-213. [PubMed: 16991914]

Hagbarth KE, Kerr DIB. Central influences on spinal afferent conduction. J. Neurophysiol. 1954; 17:295-307. [PubMed: 13163716]

Halliday, AM.; Logue, V. Painful sensation evoked by electrical stimulation in the thalamus. In: Somjen, GG., editor. Neurophysiology Studied in Man. Excerpta Medica Foundation; Amsterdam: 1972. p. 221-230.

Hartline, HK. [December 12, 1967] Visual receptors and retinal interaction. Nobel Lecture. 1967. http://nobelprize.org/nobel_prizes/medicine/laureates/1967/hartline-lecture.pdf

Hassler R. Die zentralen systeme des schmerzes. Central pain systems. Acta Neurochir. 1960; 8:353423.

Head, H. Studies in Neurology. Oxford University Press; London: 1920.

Head H, Holmes G. Sensory disturbances from cerebral lesions. Brain. 1911; 34:102-254.

Heinbecker P, Bishop GH, O’Leary J. Pain and touch fibers in peripheral nerves. Arch. Neurol. Psychiatry. 1933; 29:771-789.

Hofbauer RK, Rainville P, Duncan GH, Bushnell MC. Cortical representation of the sensory dimensino of pain. J. Neurophysiol. 2001; 86:402-411. [PubMed: 11431520]

Honda CN, Mense S, Perl ER. Neurons in ventrobasal region of cat thalamus selectively responsive to noxious mechanical stimulation. J. Neurophysiol. 1983; 49:662-73. [PubMed: 6300352]

Hucho T, Levine JD. Signaling pathways in sensitization: toward a nociceptor cell biology. Neuron. 2007; 55:365-376. [PubMed: 17678851] 
Hughes DI, Scott DT, Todd AJ, Riddell JS. Lack of evidence for sprouting of A $\beta$ afferents into the superficial laminas of the spinal cord dorsal horn after nerve section. J. Neurosci. 2003; 23:94919499. [PubMed: 14573528]

Hunt CC, McIntyre AK. An analysis of fibre diameter and receptor characteristics of myelinated cutaneous afferent fibers in cat. J. Physiol. 1960; 153:99-112. [PubMed: 14405412]

Iggo A. Cutaneous heat and cold receptors with slowly conducting (C) afferent fibres. Quart. J. Exp. Physiol. 1959a; 44:362-370. [PubMed: 13852621]

Iggo, A. Ciba Foundation Study Group, No. 1. J. \& A. Churchill, Ltd.; London: 1959b. A single unit analysis of cutaneous receptors with $\mathrm{C}$ afferent fibers; p. 41-56.

Iggo A. Cutaneous mechanoreceptors with afferent C fibres. J. Physiol. 1960; 152:337-353. [PubMed: 13852622]

International Association for the Study of Pain. [accessed 24 February 2011] IASP pain terminology (neuropathic pain). 2011.

http://www.iasp-pain.org/AM/Template.cfm?Section=Pain_Defi...isplay.cfm\&ContentID=1728

Jankowski MP, Lawson JJ, McIlwrath SL, Rau KK, Anderson CE, Albers KM, Koerber HR. Sensitization of cutaneous nociceptors after nerve transection and regeneration: possible role of target-derived neurotrophic factor signaling. J. Neurosci. 2009; 29:1636-1647. [PubMed: 19211871]

Jones AKP, Kulkarni B, Derbyshire SWG. Pain mechanisms and their disorders. Brit. Med. Bull. 2003; 65:83-93. [PubMed: 12697618]

Jones, EG. The Thalamus. Plenum Press; New York: 1985.

Jones, EG. The Thalamus. Cambridge University Press; Cambridge: 2007.

Jones, SL. Descending control of nociception. In: Light, AR., editor. The Initial Processing of Pain and Its Descending Control: Spinal and Trigeminal Systems. Vol. Vol. 12. Karger; Basel: 1992. p. 203-295.

Julius D, Basbaum AI. Molecular mechanisms of nociception. Nature. 2001; 413:203-210. [PubMed: 11557989]

Keele, KD. Anatomies of Pain. Charles C Thomas; Springfield, Ill: 1957.

Kenshalo DR, Isensee O. Responses of primate SI cortical neurons to noxious stimuli. J. Neurophysiol. 1983; 50:1479-1496. [PubMed: 6663338]

Kenshalo DR, Iwata K, Sholas M, Thomas DA. Response properties and organization of nociceptive neurons in area 1 of monkey primary somatosensory cortex. J. Neurophysiol. 2000; 84:719-29. [PubMed: 10938299]

Kenshalo, DR., Jr.; Willis, WD, Jr.. The role of the cerebral cortex in pain sensation. In: Peters, A.; Jones, EG., editors. Cerebral Cortex: Normal and Altered States of Function. Vol. Vol. 9. Plenum; New York: 1991. p. 153-212.

Kenshalo DR Jr. Chudler EH, Anton F, Dubner R. SI nociceptive neurons participate in the encoding process by which monkeys perceive the intensity of noxious thermal stimulation. Brain Res. 1988; 454:378-82. [PubMed: 3409021]

Kenshalo DR Jr. Giesler GJ Jr. Leonard RB, Willis WD. Responses of neurons in primate ventral posterior lateral nucleus to noxious stimuli. J. Neurophysiol. 1980; 43:1594-614. [PubMed: 7411178]

Kim SH, Chung JM. An experimental model for peripheral neuropathy produced by segmental spinal nerve ligation in the rat. Pain. 1992; 50:355-363. [PubMed: 1333581]

King RB. Anterior commissurotomy for intractable pain. J. Neurosurg. 1977; 47:7-11. [PubMed: 68111]

Kleist, K. Kriegsverletzungen des Gehirns in ihrer Bedeutung für die Hirnlokalisation und Hirnpathologie. In: von Schjerning, O., editor. Handbuch der Artzlichen Erfahrungen im Weltkriege 1914-1918 Geistesund Nervenkrankheiten. Barth; Leipzig, Germany: 1934. p. 343-1393.

Koerber HR, Woodbury CJ. Comprehensive phenotyping of sensory neurons using an ex vivo somatosensory system. Physiol. Behav. 2002; 77:589-594. [PubMed: 12527004] 
Kumazawa T, Perl ER. Primate cutaneous sensory units with unmyelinated (C) afferent fibers. J. Neurophysiol. 1977; 40:1325-1338. [PubMed: 411895]

Kumazawa T, Perl ER. Excitation of marginal and substantia gelatinosa neurons in the primate spinal cord: indication of their place in dorsal horn functional organization. J. Comp. Neurol. 1978; 177:417-434. [PubMed: 412881]

Kumazawa T, Perl ER, Burgess PR, Whitehorn D. Ascending projections from marginal zone (lamina I) neurons of the spinal dorsal horn. J. Comp. Neurol. 1975; 162:1-11.

Kuner R. Central mechanisms of pathological pain. Nat. Med. 2010; 16:1258-1266. [PubMed: 20948531]

Kuno M, Perl ER. Alteration of spinal reflexes by interaction with suprasegmental and dorsal root activity. J. Physiol. 1960; 151:103-122. [PubMed: 14412770]

Kuru, M. The Sensory Paths in the Spinal Cord and Brain Stem of Man. Sogensya; Tokyo: 1949.

Landau W, Bishop GH. Pain from dermal, periosteal, and fascial endings and from inflammation. A.M.A. Arch. Neurol. Psychiat. 1953; 69:490-504.

Latremoliere A, Woolf CJ. Central sensitization: a generator of pain hypersensitivity by central neural plasticity. J. Pain. 2009; 10:895-926. [PubMed: 19712899]

LaVail JH, LaVail MM. Retrograde axonal transport in the central nervous system. Science. 1972; 176:1416-1417. [PubMed: 5033648]

Lembeck F. Sir Thomas Lewis's nocifensor system, histamine and substance-P-containing primary afferent nerves. Trends Neurosci. 1983; 6:106-108.

Lembeck, F. A Network of Defense. In: Henry, JL.; Couture, R.; Cuello, A.; Pelletier, G.; Quirion, R.; Regoli, D., editors. Substance P and Neurokinins. Springer; Berlin: 1987. p. 380-387.

Lenz FA, Gracely RH, Rowland LH, Dougherty PM. A population of cells in the human thalamic principal sensory nucleus respond to painful mechanical stimuli. Neurosci. Lett. 1994; 180:4650. [PubMed: 7877759]

Lenz FA, Seike M, Lin YC, Baker FH, Rowland LH, Gracely RH, Richardson RT. Neurons in the area of human thalamic nucleus ventralis caudalis respond to painful heat stimuli. Brain Res. 1993a; 623:235-40. [PubMed: 8221105]

Lenz FA, Seike M, Richardson RT, Lin YC, Baker FH, Khoja I, Jaeger CJ, Gracely RH. Thermal and pain sensations evoked by microstimulation in the area of human ventrocaudal nucleus. J. Neurophysiol. 1993b; 70:200-12. [PubMed: 8360716]

Levine JD, Taiwo YO. Hyperalgesic pain: a review. Anesth. Prog. 1990; 37:133-135. [PubMed: 1964769]

Lewis T. The nocifensor system of nerves and its reactions. Brit. Med. J. 1937; 1:431-435. 491-494. [PubMed: 20780499]

Lewis T, Pochin EE. The double pain response of the human skin to a single stimulus. Clin. Sci. 1937; 3:67-76.

Lewis T, Pickering GW, Rothschild P. Centripetal paralysis arising out of arrested bloodflow to the limb, including notes on a form of tingling. Heart. 1931; 16:1-32.

Light, AR. The Initial Processing of Pain and its Descending Control: Spinal and Trigeminal Systems. S. Karger AG; Basel: 1992.

Light AR, Perl ER. Spinal termination of functionally identified primary afferent neurons with slowly conducting myelinated fibers. J. Comp. Neurol. 1979; 186:133-150. [PubMed: 109477]

Light AR, Trevino DL, Perl ER. Morphological features of functionally defined neurons in the marginal zone and substantia gelatinosa of the spinal dorsal horn. J. Comp. Neurol. 1979; 186:151-172. [PubMed: 447881]

Linderoth B, Meyerson BA. Spinal cord stimulation: exploration of the physiological basis of a widely used therapy. Anesthesiology. 2010; 113:1265-1267. [PubMed: 21042195]

Lynn B, Carpenter SE. Primary afferent units from the hairy skin of the rat hind limb. Brain Res. 1982; 238:23-43.

Magendie F. Expériences sur les fonctions des racines des nerfs qui naissent de la moëlle épinière. J. Physiol. Expér. Pathol. 1822; 2:366-371. 
Mantyh PW. Neurobiology of substance P and the NK1 receptor. J. Clin. Psychiatry. 2002; 63(Suppl 11):6-10. [PubMed: 12562137]

Marshall J. Sensory disturbances in cortical wounds with special reference to pain. J. Neurol. Neurosurg. Psychiatry. 1951; 14:187-204. [PubMed: 14874132]

Maruhashi J, Mizuguchi K, Tasaki I. Action currents in single afferent nerve fibres elicited by stimulation of the skin of the toad and the cat. J. Physiol. 1952; 117:129-151. [PubMed: 14955805]

Mason P. Contributions of the medullary raphe and ventromedial reticular region to pain modulation and other homeostatic functions. Annu. Rev. Neurosci. 2001; 24:737-77. [PubMed: 11520917]

Mason P. Deconstructing endogenous pain modulations. J. Neurophysiol. 2005; 94:1659-63. [PubMed: 16105951]

Matthews BHC. Nerve endings in mammalian muscle. J. Physiol. 1933; 78:1-53. [PubMed: 16994401]

May A. Neuroimaging: visualising the brain in pain. Neurol. Sci. 2007; 28:S101-S107. [PubMed: 17508154]

Mayer DJ, Price DD, Becker DP. Neurophysiological characterization of the anterolateral spinal cord neurons contributing to pain perception in man. Pain. 1975; 1:51-58. [PubMed: 829276]

Mehler WR, Feferman ME, Nauta WJH. Ascending axon degeneration following anterolateral cordotomy. An experimental study in the monkey. Brain. 1960; 83:718-750. [PubMed: 13768983]

Melzack R, Wall PD. On the nature of cutaneous sensory mechanisms. Brain. 1962; 85:331-356. [PubMed: 14472486]

Melzack R, Wall PD. Pain mechanisms: A new theory. Science. 1965; 150:971-979. [PubMed: 5320816]

Mendell LM. Physiological properties of unmyelinated fiber projection to the spinal cord. Exp. Neurol. 1966; 16:316-332. [PubMed: 5928985]

Meyerson BA, Linderoth B. Mode of action of spinal cord stimulation in neuropathic pain. J. Pain Symptom Manage. 2006; 31:S6-S12. [PubMed: 16647596]

Mott FW. Experimental enquiry upon the afferent tracts of the central nervous system of the monkey. Brain. 1895; 18:1-20.

Mountcastle VB, Powell TPS. Neural mechanisms subserving cutaneous sensibility, with special reference to the role of afferent inhibition in sensory perception and discrimination. Bull. Johns Hopkins Hosp. 1959; 105:201-232. [PubMed: 14424738]

Müller, J. Handbuch der Physiologie des Menschen. J. Holscher; Koblenz, Germany: 1840.

Nafe JP. A quantitative theory of feeling. J. Gen. Psychol. 1929; 2:199-211.

Nafe, JP. The pressure, pain, and temperature senses. In: Murchison, C., editor. Handbook of General Experimental Psychology. Clark University Press; Wooster, MA: 1934. p. 1037-1087.

O'Callaghan JP, Miller DB. Spinal glia and chronic pain. Metab. Clin. Exp. 2010; 59(Suppl 1):S21S26. [PubMed: 20837189]

Pagni, CA. Central Pain: A Neurosurgical Challenge. Edizioni Minerva medica; Torino: 1998.

Paintal AS. Responses from mucosal mechanoreceptors in the small intestine of the cat. J. Physiol. 1957; 139:353-68. [PubMed: 13492228]

Paintal AS. Functional analysis of group III afferent fibres of mammalian muscles. J. Physiol. 1960; 152:250-270. [PubMed: 14429833]

Penfield W, Boldrey E. Somatic motor and sensory representation in the cerebral cortex of man as studied by electrical stimulation. Brain. 1937; 60:389-443.

Perl ER. Myelinated afferent fibers innervating the primate skin and their response to noxious stimuli. J. Physiol. 1968; 197:593-615. [PubMed: 4969883]

Perl ER, Whitlock DG. Somatic stimuli exciting spinothalamic projections to thalamic neurons in cat and monkey. Exp. Neurol. 1961; 3:256-296. [PubMed: 13734415]

Peyron R, Laurent B, Garcia-Larrea L. Functional imaging of brain responses to pain. A review and meta-analysis (2000). Neurophysiol. Clin. 2000; 30:263-88. [PubMed: 11126640] 
Price DD, Dubner R. Neurons that subserve the sensory-discriminative aspects of pain. Pain. 1977; 3:307-338. [PubMed: 198724]

Price DD, Mayer DJ. Neurophysiological characterization of the anterolateral quadrant neurons subserving pain in M. Mulatta. Pain. 1975; 1:59-72. [PubMed: 829277]

Ramon y Cajal, S. Histologie du Systèm Nerveux de l'Homme et des Vertébrés. Maloine; Paris: 1909.

Ranson SW. The course within the spinal cord of the non-medullated fibers of the dorsal roots: a study of Lissauer's tract in the cat. J. Comp. Neurol. 1913; 23:259-281.

Ranson SW. The tract of Lissauer and the substantia gelatinosa rolandi. Am. J. Anat. 1914; 16:97-126.

Ranson SW. Unmyelinated nerve-fibres as conductors of protopathic sensation. Brain. 1915; 38:381389.

Ranson SW, Billingsley PR. The conduction of painful afferent impulses in the spinal nerves. Am. J. Physiol. 1916; 40:571-584.

Ren K, Dubner R. Interactions between the immune and nervous systems in pain. Nature Medicine. 2010; 16:1267-1276.

Rey, R. History of Pain. Editions la Découverte; Paris: 1993.

Reynolds DV. Surgery in the rat during electrical analgesia induced by focal brain stimulation. Science. 1969; 164:444-445. [PubMed: 4887743]

Russell WR. Transient disturbances following gunshot wounds of the head. Brain. 1945; 68:79-97. [PubMed: 21010584]

Schiff, JM. Lehrbuch der Physiologie des Menschen. Muskel und Nervenphysiologie. Schauenberg; Lahr: 1858.

Schwann, T. Microscopical Researches into the Accordance in the Structure and Growth of Animals and Plants. Printed for the Syndenham Society; London: 1847.

Seltzer Z, Dubner R, Shir Y. A novel behavioral model of neuropathic pain disorders produced in rats by partial sciatic nerve injury. Pain. 1990; 43:205-218. [PubMed: 1982347]

Sherrington, CS. The Integrative Action of the Nervous System. Cambridge University Press; Cambridge: 1906.

Shu XQ, Mendell LM. Neurotrophins and hyperalgesia. Proc. Natl. Acad. Sci. USA. 1999; 96:76937696. [PubMed: 10393882]

Sinclair DC. Cutaneous sensation and the doctrine of specific energy. Brain. 1955; 78:584-614. [PubMed: 13293271]

Sinclair DC, Weddell G, Zander E. The relationship of cutaneous sensibility to neurohistology in the human pinna. J. Anat. 1952; 86:402-411. [PubMed: 12999642]

Spiller WG. The occasional clinical resemblance between caries of the vertebrae and lumbothoracic syringomyella, and the location within the spinal cord of the fibres for the sensation of pain and temperature. Univ. Pa. Med. Bull. 1905; 18:147-154.

Spiller WG, Martin E. The treatment of persistent pain of organic origin in the lower part of the body by division of the anterolateral column of the spinal cord. J. Am. Med. Assoc. 1912; 58:14891490.

Thunberg T. Untersuchungen über die relative Tiefenlage der kältewärme-, und schmerzpercipirenden Nervenenden in der Haut und über das Verhältniss der Kältenervenenden gegenüber Wärmereizen. Skand. Arch. Physiol. 1901; 11:382-435.

Torebjörk E. Nociceptor activation and pain. Philos. Trans. R. Soc. Lond. B Biol. Sci. 1985; 308:227234. [PubMed: 2858880]

Torebjörk HE. Afferent $\mathrm{C}$ units responding to mechanical, thermal and chemical stimuli in human nonglabrous skin. Acta Physiol. Scand. 1974; 92:374-390. [PubMed: 4141858]

Torebjörk HE, Schady W, Ochoa J. Sensory correlates of somatic afferent fibre activation. Hum. Neurobiol. 1984; 3:15-20. [PubMed: 6330006]

Treede RD, Apkarian AV, Bromm B, Greenspan JD, Lenz FA. Cortical representation of pain: functional characterization of nociceptive areas near the lateral sulcus. Pain. 2000; 87:113-9. [PubMed: 10924804] 
Treede RD, Meyer RA, Campbell JN. Comparison of heat and mechanical receptive fields of cutaneous C-fiber nociceptors in monkey. J. Neurophysiol. 1990; 64:1502-1513. [PubMed: 2283538]

Trevino DL, Carstens E. Confirmation of the location of spinothalamic neurons in the cat and monkey by the retrograde transport of horseradish peroxidase. Brain Res. 1975; 98:177-182. [PubMed: 809119]

Trevino DL, Coulter JD, Willis WD. Excitation of cells of origin of the spinothalamic tract of the monkey. Fed. Proc. 1972a; 31:385.

Trevino DL, Coulter JD, Willis WD. Location of cells of origin of spinothalamic tract in lumbar enlargement of the monkey. J. Neurophysiol. 1973; 36:750-761. [PubMed: 4197341]

Trevino DL, Maunz RA, Bryan RN, Willis WD. Location of cells of origin of the spinothalamic tract in the lumbar enlargement of cat. Exp. Neurol. 1972b; 34:64-77. [PubMed: 5009510]

Vogt, BA.; Sikes, RW.; Vogt, LJ. Anterior cingulate cortex and the medial pain system. In: Vogt, BA.; Gabriel, M., editors. Neurobiology of Cingulate Cortex and Limbic Thalamus: A Comprehensive Handbook. Birkhäuser; Boston: 1993. p. 313-344.

Waldeyer W. Über einige neurere Forschungen in Gebiete der Anatomie des Centralnervensystems. Deutsche Med. Wochenschr. 1891; 44:1-64.

Walker, AE. The Primate Thalamus. University of Chicago Press; Chicago: 1938.

Wang LX, Wang ZJ. Animal and cellular models of chronic pain. Adv. Drug Deliv. Rev. 2003; 55:949-965. [PubMed: 12935939]

Weddell G. Somesthesis and the chemical senses. Ann. Rev. Psychol. 1955; 6:119-136. [PubMed: 14377361]

White, JC.; Sweet, WH. End organs, afferent tracts, and central stations concerned with the transmission and appreciation of pain. In: Thomas, CC., editor. Pain: Its Mechanisms \& Neurosurgical Control. Springfield: 1955. p. 9-66.

Willis, WD. The Pain System. Karger; Basel: 1985.

Willis WD. Role of neurotransmitters in sensitization of pain responses. Ann. NY Acad. Sci. 2006; 933:142-156. [PubMed: 12000017]

Willis, WD.; Coggeshall, RE. Sensory Mechanisms of the Spinal Cord. Plenum Press; New York: 1991.

Willis WD, Westlund KN. Neuroanatomy of the pain system and of the pathways that modulate pain. J. Clin. Neurophysiol. 1997; 14:2-31. [PubMed: 9013357]

Willis WD Jr. Zhang X, Honda CN, Giesler GJ Jr. A critical review of the role of the proposed VMpo nucleus in pain. J. Pain. 2002; 3:79-94. [PubMed: 14622792]

Willis WD, Kenshalo DR, Leonard RB. The cells of origin of the primate spinothalamic tract. J. Comp. Neurol. 1979; 188:543-574. [PubMed: 118192]

Woollard HH, Weddell G, Harpman JA. Observations on the neurohistological basis of cutaneous pain. J. Anat. 1940; 74:413-439. [PubMed: 17104827]

Yoshino A, Okamoto Y, Onada K, Yoshimura S, Kunisato Y, Demoto Y, Yamawaki S. Sadness enhances the experience of pain via neural activation in the anterior cingulate cortex and amygdala: An fMRI study. NeuroImage. 2010; 50:1194-1201. [PubMed: 19969094]

Zeilhofer HU. Prostanoids in nociception and pain. Biochem. Pharmacol. 2007; 73:165-174. [PubMed: 16959219]

Zimmermann M. Dorsal root potentials after C-fiber stimulation. Science. 1968; 160:896-898. [PubMed: 5239306]

Zotterman Y. Studies in the peripheral nervous mechanism of pain. Acta Med. Scand. 1933; 80:1-64.

Zotterman Y. Specific action potentials in the lingual nerve of cat. Skand. Arch. Physiol. 1936; 75:105-120.

Zotterman Y. Touch, pain and tickling: an electrophysiological investigation on cutaneous sensory nerves. J. Physiol. 1939; 95:1-28. [PubMed: 16995068]

Zylka MJ, Dong X, Southwell AL, Anderson DJ. Atypical expansion in mice of the sensory neuronspecific Mrg G protein-coupled receptor family. Proc. Natl. Acad. Sci. USA. 2003; 100:1004310048. [PubMed: 12909716] 


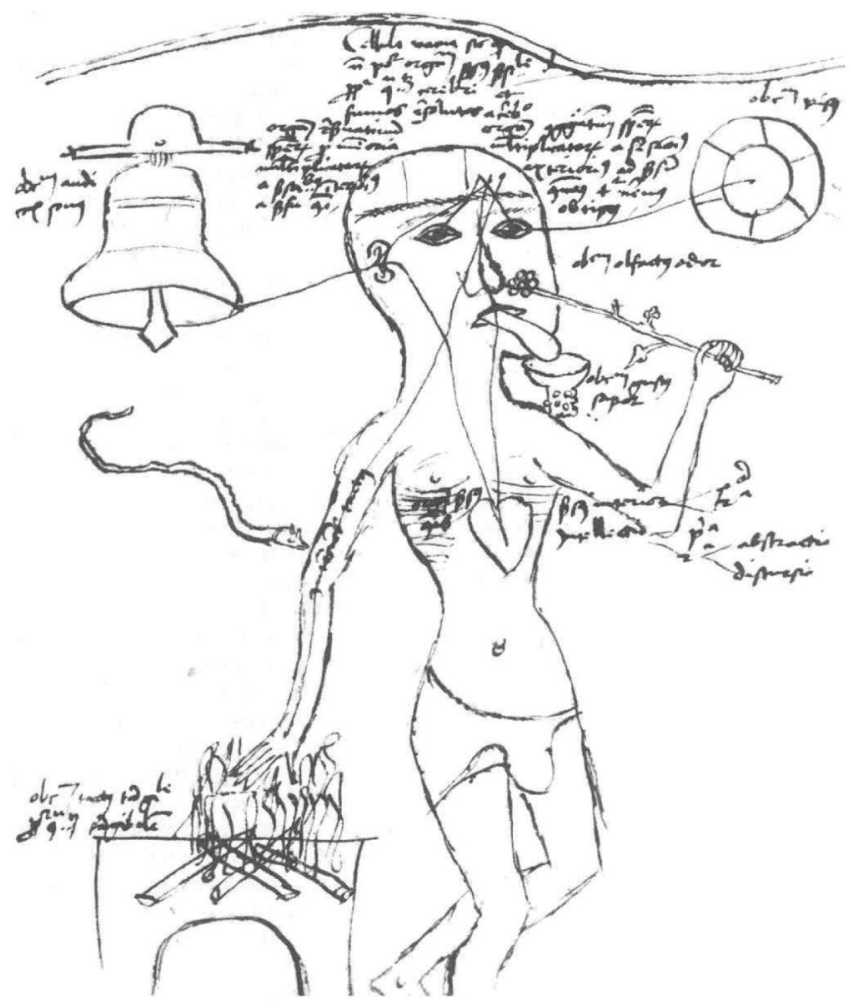

Figure 1.

A late $15^{\text {th }}$-century drawing portraying ideas about sensation in the early Renaissance. It depicts the Aristotelian view of the heart as the seat of sensation with modifications by concepts that follow Galen's and Avicenna's views of the importance of nerves and nervous system. Several senses are considered - audition, vision, smell, taste, and pain. Pain from heat or snakebite is shown, as are paths to the brain and from the brain to the heart. The heart is called "the sensus communis." It is unclear whether the artist meant to show the concept of sensation derived from particles of the environment being carried to the brain or Newton's later view that messages in nerves were vibrations of the substance of nerve fibers. (From G. Harderwyck, Epitomata seu Reparationes totius philosophiae naturalis Aristotelis, Colonia: H. Quentell, 1496. Reproduced with permission of the Wellcome Library, London.) 


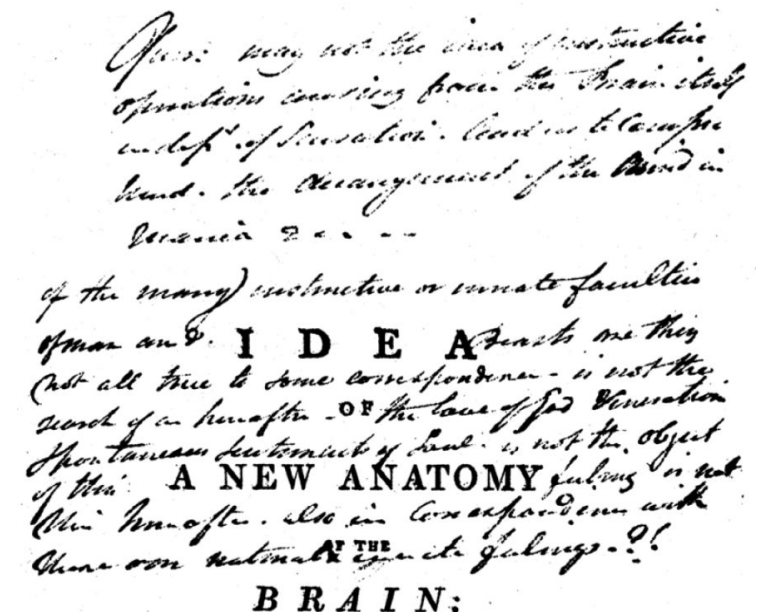

EvBMrtTED

FOR THE OBSERVATIONS OF HIS FRENDDS;

B

CHARLES BELL, F.R.S.E.

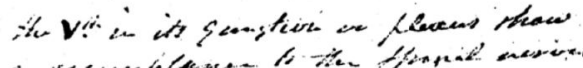

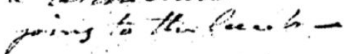

Figure 2.

Title page of a pamphlet privately published in 1811 by the Edinburgh anatomist/physician, Charles Bell, entitled Idea of a New Anatomy of the Brain. The monograph describes Bell's concept of the functional difference between the spinal dorsal and ventral roots and presents his ideas about specific sensory function. (From Bell, C., Idea of a New Anatomy of the Brain; Submitted for the Observations of His Friends. Strahan and Preston: London, 1811. Used with permission of The Royal Society.) 


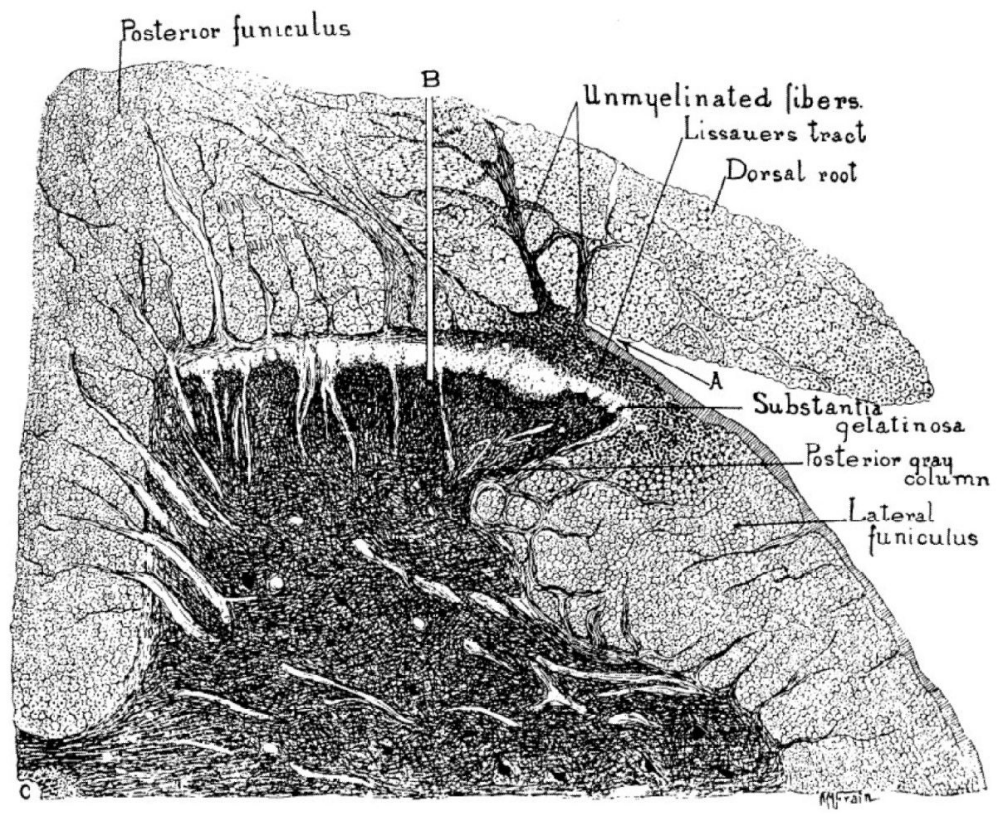

Figure 3.

Drawing of a transverse section of a cat lumbar spinal segment illustrating the dorsal root division into medial and lateral bundles. This feature was used by Ranson and Billingsley (1916) to establish that interruption of the lateral division (A), but not the medial (B), interferes with primary afferent activity evoking pain-like behavior. (From Ranson, S. W. and Billingsley, P. R., The conduction of painful afferent impulses in the spinal nerves. Am. J. Physiol. 40, 571-584, 1916. Used with permission.) 


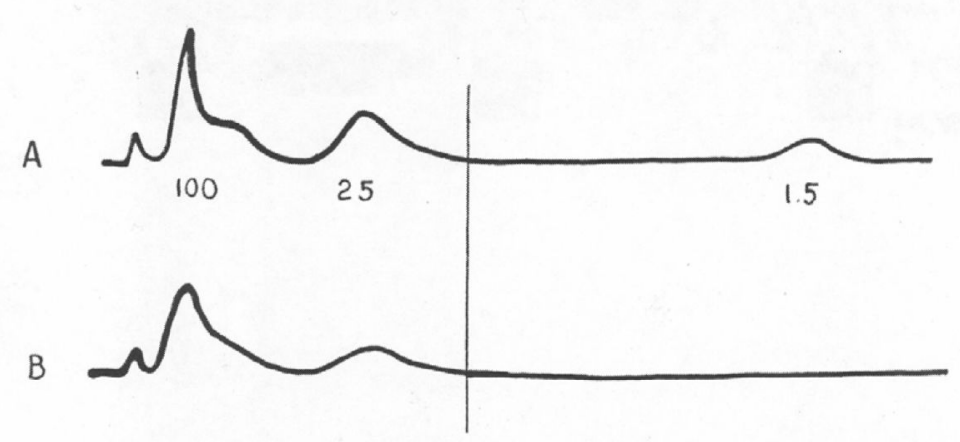

Figure 4.

Reproduction of compound action potentials recorded from a human cutaneous nerve (Heinbecker et al., 1933). A: response recorded at an electrical stimulus strength sufficient to excite all of the nerve's fibers. The numbers underneath the tracing indicate conduction velocities for the first part of each deflection (in $\mathrm{m} / \mathrm{s}$ ). B: the response recorded at the stimulus intensity reported by the conscious subject to cause painful sensation. The vertical lines indicate the components that appeared at the threshold for the painful report. (Arch. Neurol. Psychiatry 29, 771-789. Copyright (C) 1933, American Medical Association. All rights reserved.) 


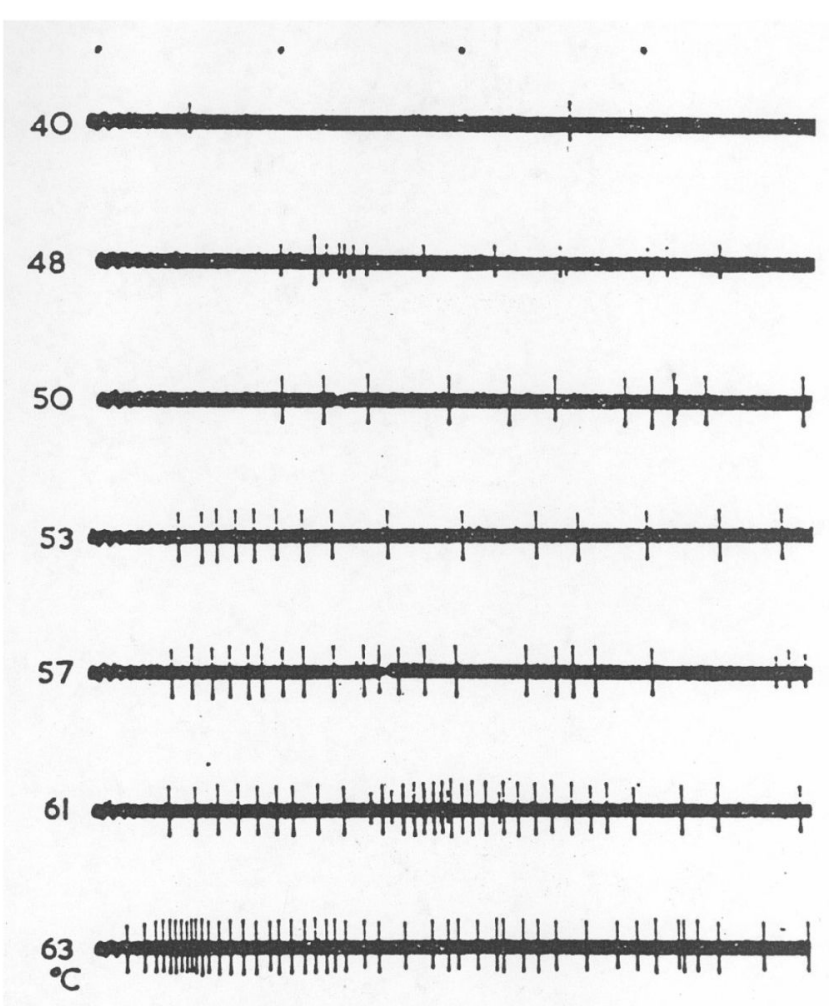

Figure 5.

Activity of an unmyelinated cat cutaneous afferent fiber that was excited by skin contact with a probe heated to noxious levels. Responses to a graded series of probe temperatures is shown. The left of each trace shows the temperature $\left({ }^{\circ} \mathrm{C}\right)$ of the contact probe used as a stimulus. (From Iggo, [1959] A single unit analysis of cutaneous receptors with C afferent fibers. In: Ciba Foundation Study Group, No. 1, pp. 41-56. J. \& A. Churchill, Ltd.: London. Reproduced with the permission of A. Iggo.) 


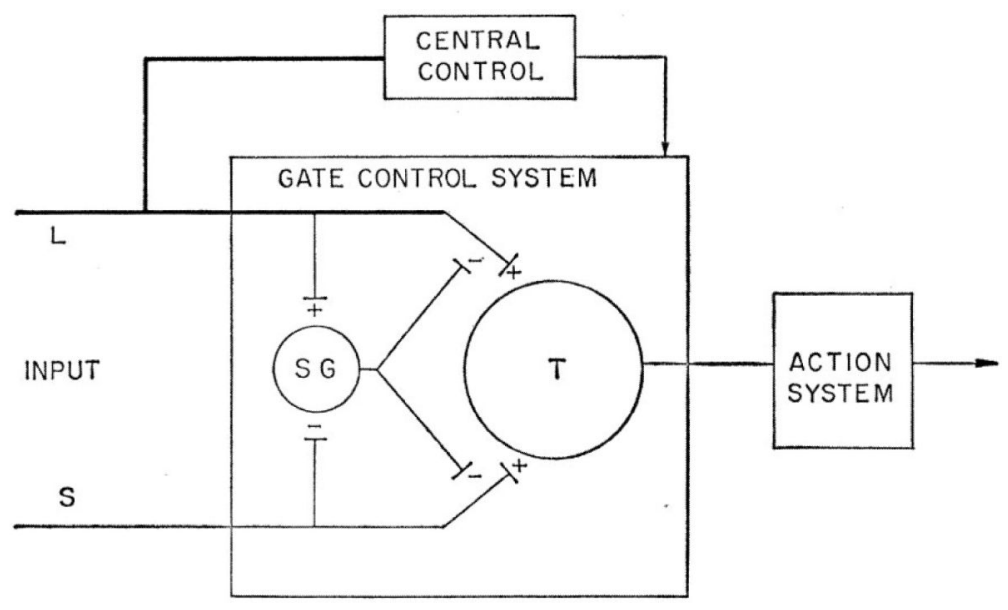

Figure 6.

Cartoon showing hypothesized mechanisms proposed in the Gate Control Theory for Pain (Melzack and Wall, 1965). $\mathbf{L}$ indicates large-diameter primary afferent fibers. $\mathbf{S}$ indicates small-diameter primary afferent fibers. Both types of primary afferent fibers are proposed to project to the spinal substantia gelatinosa (SG). In the proposal, activity in the L fibers excites whereas that in the S fibers inhibits the SG neurons. The SG cells are hypothesized to act presynaptically at junctions of the $\mathrm{L}$ and $\mathrm{S}$ fibers with $\mathrm{SG}$ transmission cells (T). The SG gate is presumed to be closed by activity in the L fibers and opened by activity in the S fibers. In addition to dynamically balanced activity from the SG, the gate control theory presumes central nervous system control of the spinal gate by pathways descending from rostral CNS centers. The descending pathways are postulated to operate upon the net L- and S-fiber activity to inhibit activation of T cells and the action system. Many questions have been raised about operation of the gate hypothesis for pain as originally proposed, shown in this diagram, and subsequently modified. (From Melzack, R. and Wall, P. D., Pain mechanisms: A new theory. Science 150, 971-979, 1965. Reprinted with permission from AAAS.) 
A
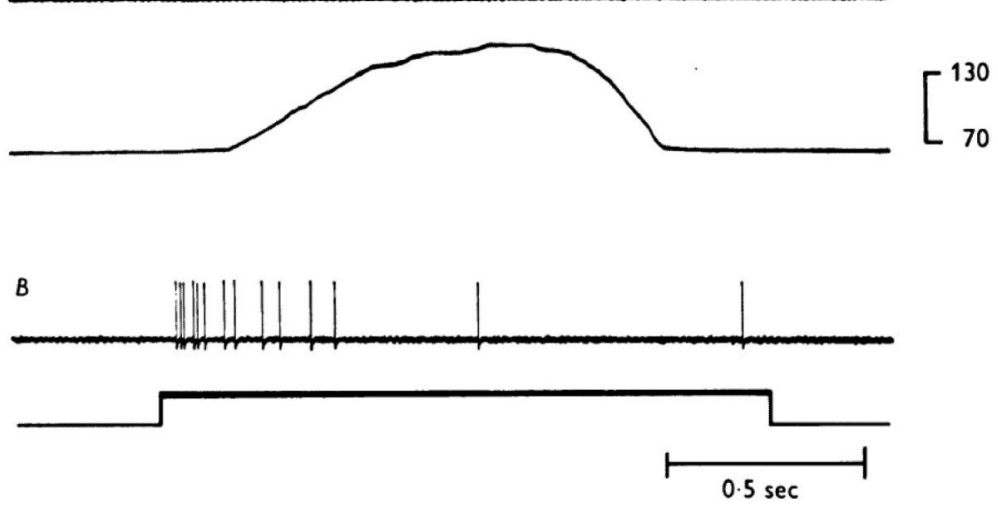

Figure 7.

Responses of a nociceptive myelinated afferent fiber to mechanical stimulation of its cutaneous receptive field. Fiber conduction velocity, $25 \mathrm{~m} / \mathrm{s}$. Upper of each pair of traces displays the action potentials evoked in the fiber. The fiber had a highly elevated threshold to mechanical stimulation of the skin and did not respond to temperature stimuli $\left(20^{\circ} \mathrm{C}\right.$ to $55^{\circ} \mathrm{C}$ ). The lower trace of each pair indicates the time of mechanical stimulation of the skin. A shows the force exerted by a rounded, neutral-temperature probe applied to the receptive field. B: Response evoked by a pinch of the skin with a serrated tissue forceps, producing visible damage of the skin surface. (From Burgess, P. R. and Perl, E. R. (1967) Myelinated afferent fibres responding specifically to noxious stimulation of the skin. J. Physiol. 190, 541-562.) 


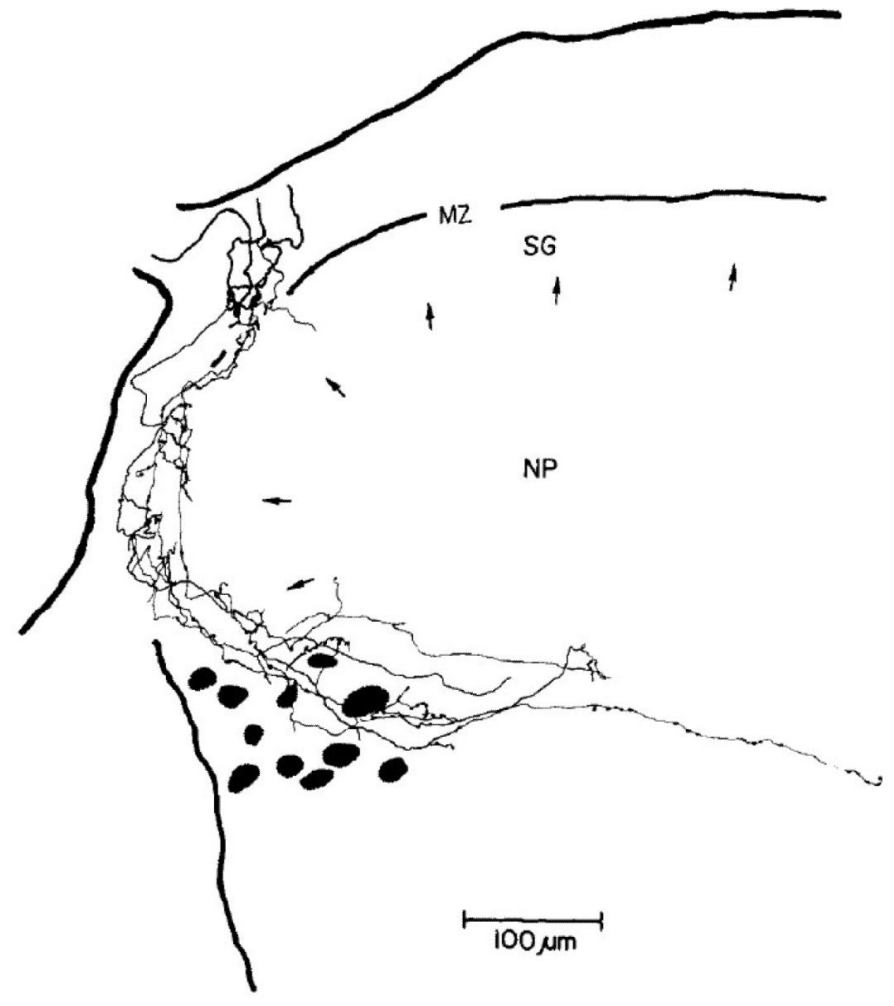

Figure 8.

The spinal distribution of projections by a myelinated afferent fiber from a cutaneous mechanical nociceptor. Electrophysiological recordings established the functional characteristics of the response to cutaneous stimulation; the fiber was then labeled with horseradish peroxidase from the recording microelectrode. The fiber distribution was visualized by histochemical processing for the peroxidase. Fiber conduction velocity was 16 $\mathrm{m} / \mathrm{s}$. The terminal distribution of the fiber was reconstructed from multiple transverse histological sections. The pattern of endings in laminae $\mathrm{I}$ and $\mathrm{II}_{\mathrm{O}}$ of the spinal dorsal horn is typical of this class of nociceptors and uniquely different from low-threshold myelinated mechanoreceptors or of unmyelinated afferent units. Arrow tips indicate the boundary between lamina II (SG) and deeper laminae of the dorsal horn. (From Light, A.R. and Perl, E.R. Spinal termination of functionally identified primary afferent neurons with slowly conducting myelinated fibers. J. Comp. Neurol. 186[2]: 133-150, 1979. Copyright 1979, John Wiley \& Sons, Inc. Reprinted with permission of John Wiley \& Sons, Inc.) 


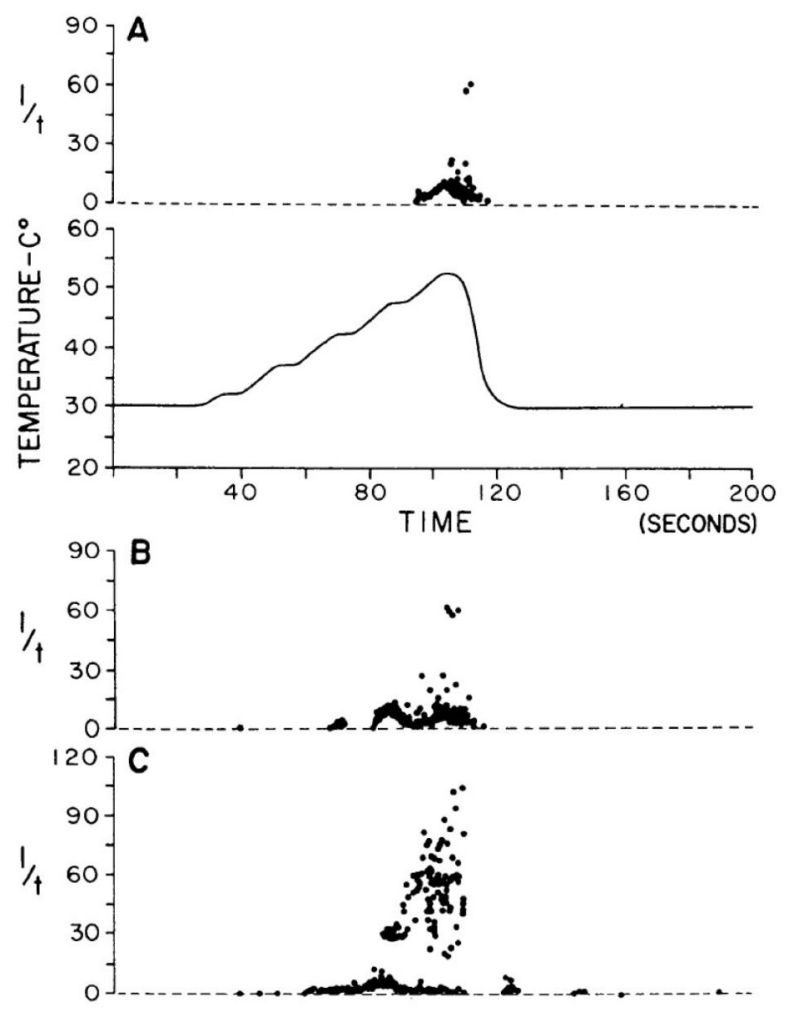

Figure 9.

An example of nociceptors sensitization: responses of a monkey C-fiber cutaneous polymodal nociceptor to repeated noxious heating by a contact probe. A: the upper plot indicates the discharge of the unit evoked by the first heating of the skin to noxious levels. Each recorded discharge is displayed as a dot scaled on the ordinate according to the reciprocal of the time between it and the previous impulse ("instantaneous frequency"). The lower trace indicates the skin probe temperature, automatically programmed to sequence step increases from $30^{\circ} \mathrm{C}$ to approximately $55^{\circ} \mathrm{C}$. The stimulus sequence was repeated at 200-s intervals. B: The response for the third stimulus sequence. C: The response to the fifth repetition of the heating sequence. Note the progressive increase in the number of impulses evoked by repeated identical stimuli and the higher repetition rate (shorter intervals) produced in the third and fifth repetitions. (From Kumazawa, T. and Perl, E. R., Primate cutaneous sensory units with unmyelinated (C) afferent fibers. J. Neurophysiol. 40, 1325-1338, 1977.) 